\title{
Dependence of aerosol-precipitation interactions on humidity in a multiple-cloud system
}

\author{
S. S. Lee \\ NOAA Earth System Research Laboratory, Chemical Sciences Division, Boulder, Colorado, USA \\ Cooperative Institute for Research in Environmental Sciences (CIRES), University of Colorado, Boulder, Colorado, USA
}

Received: 12 October 2010 - Published in Atmos. Chem. Phys. Discuss.: 29 October 2010

Revised: 23 February 2011 - Accepted: 24 February 2011 - Published: 11 March 2011

\begin{abstract}
This study examines the dependence of aerosolprecipitation interactions on environmental humidity in a mesoscale cloud ensemble (MCE) which is composed of convective and stratiform clouds. The author found that increases in aerosol concentration enhance evaporative cooling, which raises not only the intensity of vorticity and entrainment but also that of downdrafts and low-level convergence. The increase in vorticity tends to suppress precipitation. The increase in low-level convergence tends to enhance precipitation by generating more secondary clouds in a muptiple-cloud system simulated here.

At high humidity, the effect of the increased vorticity on cloud-liquid mass and, thus, precipitation is outweighed by that of the increased low-level convergence. This leads to the precipitation enhancement induced by the increase in aerosol concentration. When humidity lowers to mid humidity, the effect of aerosol on low-level convergence still dominates that on entrainment, leading to the precipitation enhancement with the increased aerosol concentration. With the lowest humidity in the current work, the effect of aerosol on entrainment dominates that on low-level convergence, leading to the precipitation suppression with the increased aerosol concentration. Hence, there is not only a competition between the effect of evaporation on vorticity and that on low-level convergence at a given humidity level but also the variation of the competition with the varying humidity. This competition and variation are absent in a single-cloud system where the effect of low-level convergence on secondary clouds is absent. This exemplifies a difference in the mechanism which controls aerosol-precipitation interactions between a singlecloud system and a multiple-cloud system.
\end{abstract}

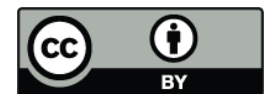

Correspondence to: S. S. Lee (seoungl@umich.edu)

\section{Introduction}

Aerosol concentration has increased significantly as a result of industrialization. Increasing aerosol concentration is known to decrease droplet size and thus increase cloud albedo for a given liquid-water content (the first aerosol indirect effect) (Twomey, 1977). They may also suppress precipitation and, hence, alter cloud-water content and lifetime (the second aerosol indirect effect) (Albrecht, 1989). The aerosol indirect effects are uncertain, but are comparable to the radiative forcing associated with the increases in anthropogenic greenhouse gases (Ramaswamy et al., 2001; Forster et al., 2007).

Xue and Feingold (2006) and Jiang et al. (2006) showed that an increasing aerosol concentration enhances the horizontal buoyancy gradient and thus induces stronger vorticity in the horizontal direction. This in turn leads to more efficient entrainment mixing with the sub-saturated cloudfree environment above the cloud base, which acts to reduce the mass of hydrometeors via their evaporation. It is likely that the effect of the increase in entrainment induced by the increase in aerosol concentration on the mass of hydrometeors gets stronger as environmental humidity lowers. Khain et al. (2008) and Lee et al. (2008a, b) showed that when a condensation enhancement induced by the increase in aerosol concentration is larger (smaller) than an evaporation enhancement, precipitation increases (diminishes). Thus, with lowering humidity, the chance of the evaporation increase being larger than the condensation increase and, thus, of the precipitation suppression induced by the increase in aerosol concentration may be higher. Khain et al. (2008) suggested that the sign of the effect of the increasing aerosol concentration on precipitation should change from the precipitation enhancement to the suppression with lowering humidity, although they did not discuss about the effect of aerosol on entrainment.

Published by Copernicus Publications on behalf of the European Geosciences Union. 
Xue and Feingold (2006) and Jiang et al. (2006) considered cases of warm cumulus clouds to study the relation among aerosol, entrainment and cloud mass. Khain et al. (2008) considered cases of a single mixed-phase cloud to examine the relation between humidity and aerosolprecipitation interactions. Evaporation of hydrometeors affects the low-level convergence of a mesoscale cloud ensemble (MCE) where deep convective clouds play an important role in dynamic and energy circulations (Khain et al., 2005; Seifert and Beheng, 2006; van den Heever et al., 2006; van den Heever and Cotton, 2007; Tao et al., 2007; Lee et al., 2008a, b, 2009, 2010; Lee and Feingold, 2010; Storer et al., 2010). Multiple deep convective clouds in the MCE grow above the freezing level to reach the tropopause. The enhancement in evaporation induced by the increase in aerosol concentration develops stronger downdrafts and, when stronger downdrafts descend below the cloud base and collide with environmental flow around the surface, low-level convergence can be intensified. The more intensified domain-averaged low-level convergence generated domain-wide more secondary clouds, inducing the more, stronger domain-averaged updrafts and thus the more domain-averaged condensation, cloud mass and precipitation (Khain et al., 2005; Seifert and Beheng, 2006; van den Heever et al., 2006; van den Heever and Cotton, 2007; Tao et al., 2007; Lee et al., 2008a, b, 2009, 2010; Lee and Feingold, 2010; Storer et al., 2010). Since lowering humidity enables more efficient evaporation, the effect of increases in aerosol concentration on low-level convergence should be stronger at lower humidity. Hence, changes in entrainment induced by the increase in aerosol concentration (which tends to increase evaporation above the cloud base and thus to reduce precipitation) is likely to compete with those in interactions between evaporation and low-level convergence below the cloud base (which tend to increase condensation and thus precipitation). This competition is likely to determine the sign of the effect of aerosol on precipitation and its dependence on humidity in a system comprising multiple clouds growing above the freezing level. Note that entrainment in this study broadly represents any processes which expose cloudy air to sub-saturated air and, thus, cause the evaporation of hydrometeors above the cloud base. Hence, entrainment in this study includes detrainment. Also, the entrainment in this study is driven not only by turbulentscale motions but also by cloud- and large-scale motions, and encompassing various scales of mixing processes. Here, cloud-scale motions involve updrafts and downdrafts, which complete the grid-resolved convection, and large-scale motions involve the large-scale wind field imposed by largescale forcings.

This study aims to gain an understanding of how this possible competition and thus the effect of aerosol on precipitation vary with environmental humidity in a MCE where deep convective clouds play an important role in precipitation. Precipitation from systems like the Asian and Indian
Monsoon, storm tracks, and the intertropical convergence zone (ITCZ) plays important roles in global hydrologic circulations (Houze, 1993). These systems are observed to be composed of numerous MCEs where deep convective clouds and associated circulations have a significant impact on precipitation (Houze, 1993). The mesoscale organization of dynamic and hydrologic circulations in the MCE is building blocks of large-scale and thus global circulations. Thus, the examination of the competition and the resulting effect of the increasing aerosol concentration on precipitation in the MCE provide a glimpse of the effect of aerosol-cloud interactions on climate.

\section{Cloud-system resolving model (CSRM)}

The Goddard Cumulus Ensemble (GCE) model (Tao et al., 2003), which is a three-dimensional nonhydrostatic compressible model, is used as a CSRM here. The detailed equations of the dynamical core of the GCE model are described by Tao and Simpson (1993) and Simpson and Tao (1993).

The subgrid-scale turbulence used in the GCE model is based on work by Klemp and Wilhelmson (1978) and Soong and Ogura (1980). In their approach, one prognostic equation is solved for the subgrid-scale kinetic energy, which is then used to specify the eddy coefficients. The effect of condensation on the generation of subgrid-scale kinetic energy is also incorporated into the model.

To represent microphysical processes, the GCE model adopts the double-moment bulk representation of Saleeby and Cotton (2004) that uses bin-model-derived lookup tables for hydrometeor collection processes. Hydrometeor size distributions assume gamma basis functions with fixed breadth. Cloud-droplet and ice-crystal nucleation also mimic a sizeresolved approach (Lee et al., 2010).

A Lagrangian scheme is used to transport the mixing ratio and number concentration of each species from any given grid cell to a lower height in the vertical column, following Walko et al. (1995).

Secondary production of ice occurs by the Hallet-Mossop process of rime splintering (Hallet and Mossop, 1974) and involves 350 ice splinters emitted for every milligram of rimed liquid at $-5.5^{\circ} \mathrm{C}$. The number of splinters per milligram of rime liquid is linearly interpolated to zero between -3 and $-8^{\circ} \mathrm{C}$.

The parameterizations developed by Chou and Suarez (1999) for shortwave radiation and by Chou et al. (1999), and Kratz et al. (1998) for longwave radiation have been implemented in the GCE model. The solar radiation scheme includes absorption due to water vapor, $\mathrm{CO}_{2}, \mathrm{O}_{3}$, and $\mathrm{O}_{2}$. Interactions among the gaseous absorption and scattering by clouds, molecules, and the surface are fully taken into account. Reflection and transmission of a cloud layer are computed using the $\delta$-Eddington approximation. Fluxes for a composite of layers are then computed using 
the two-stream adding approximation. In computing thermal infrared fluxes, the k-distribution method with temperature and pressure scaling is used to compute the transmission function.

\section{Case description}

Aerosol effects on precipitation are examined by performing two-day three-dimensional simulations of an observed MCE. The MCE was observed during a part of the TWPICE (12:00 LST (local solar time) 23 January-12:00 LST 25 January 2006) campaign in Darwin, Australia $\left(12.47^{\circ} \mathrm{N}\right.$, $130.85^{\circ} \mathrm{W}$ ), which is described by May et al. (2008) and Fridlind et al. (2009).

The TWP-ICE balloon soundings provide initial humidity and temperature and large-scale forcings of humidity and temperature. Balloon soundings of winds, temperature and dew-point temperature were obtained every $3 \mathrm{~h}$ from the observations. Vertical profiles of the initial specific humidity and potential temperature applied are shown in Fig. 1. Up to the top of the planetary boundary layer (PBL) at $1.6 \mathrm{~km}$, potential temperature and humidity increase and decrease, respectively, but generally less significantly as compared to their variations above the PBL top. The 3-hourly soundings were applied to the model as the large-scale advection for potential temperature and specific humidity at every time step by interpolation. The model domain is considered to be small compared to large-scale disturbances. Hence, the large-scale advection is approximated to be uniform over the model domain and large-scale terms are defined to be functions of height and time only. The vertical distributions of the time- and area-averaged large-scale forcings of potential temperature and specific humidity are depicted in Fig. 2. The forcing of potential temperature decreases up to $8 \mathrm{~km}$ and then increases up to $14 \mathrm{~km}$. Above $14 \mathrm{~km}$, it decreases again. The humidity forcing fluctuates between 3 and $10 \mathrm{~km}$, while it shows gradual variations at other altitudes. The observed temporally varying surface fluxes of heat and moisture were prescribed uniformly across the surface and they are identical for all of simulations in this paper. This method of modeling cloud systems was used for the CSRM comparison study by Xu et al. (2002). The details of the procedure for applying large-scale forcings are described in Donner et al. (1999) and are similar to the method proposed by Grabowski et al. (1996). The horizontal momentum was damped to observed values, following Xu et al. (2002).

The simulations of the observed MCE are referred to as CONTROL, henceforth. For CONTROL, the horizontal domain length is set at $125 \mathrm{~km}$ for both the east-west (x) and north-south (y) directions to capture mesoscale structures of the storm while the vertical domain length is set at $20 \mathrm{~km}$ to cover the troposphere and the lower stratosphere. The horizontal gird length $(\Delta x$ and $\Delta y$ ) is $500 \mathrm{~m}$ while the vertical grid length $(\Delta z)$ is $200 \mathrm{~m}$. The relatively coarse grid spacing

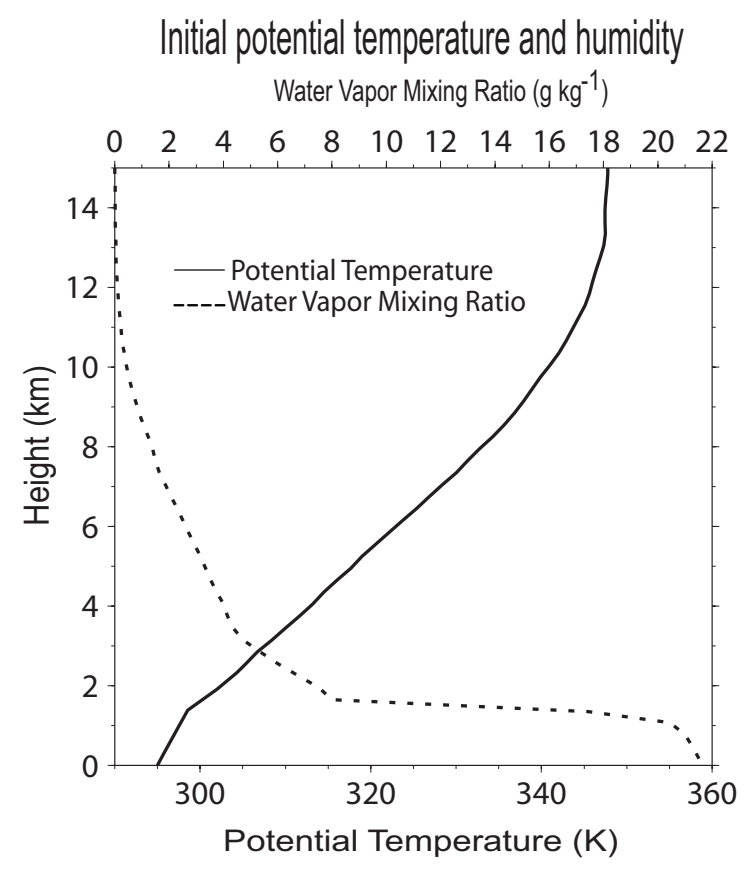

Fig. 1. Vertical profiles of initial potential temperature and water vapor mixing ratio.

(regarding the turbulent-scale entrainment) is a balance between the need to simulate the major features of the competition between entrainment and low-level convergence (but not entrainment itself) and a desire to simulate mesoscale features of the system in the large 3-D domain. Supplementary simulations with higher resolutions (which will be described in the following sections) demonstrate that this grid spacing adopted is a reasonable compromise. Periodic boundary conditions are set on horizontal boundaries. To prevent the reflection of gravity or sound waves from the model top, a damping layer of $5 \mathrm{~km}$ depth is applied near the model top.

It is assumed that there are five aerosol species: dust, sulfate, organics, black carbon, and sea salt. Aerosol bearing sulfate or organics is assumed to act only as cloud condensation nuclei $(\mathrm{CCN})$ and to be internally mixed. Dust or black carbon is assumed to be externally mixed. In this study, the well-known transformation of dust or black carbon to the soluble-coated $\mathrm{CCN}$ via coagulation with soluble substance is not considered. Hence, aerosol composed of either dust or black carbon is assumed to act only as ice nuclei. The aerosol mass mixing ratio is advected, diffused and depleted by activation during the simulation. Initially the aerosol mass mixing ratio is everywhere set equal to the background value. The aerosol number concentration in each bin of the size spectrum is determined based on the predicted aerosol mass, aerosol particle density, and an assumed log-normal size distribution. Aerosol mass is incorporated into hydrometeors during droplet or ice nucleation and is transferred among different species of hydrometeors (through collection). The 
a

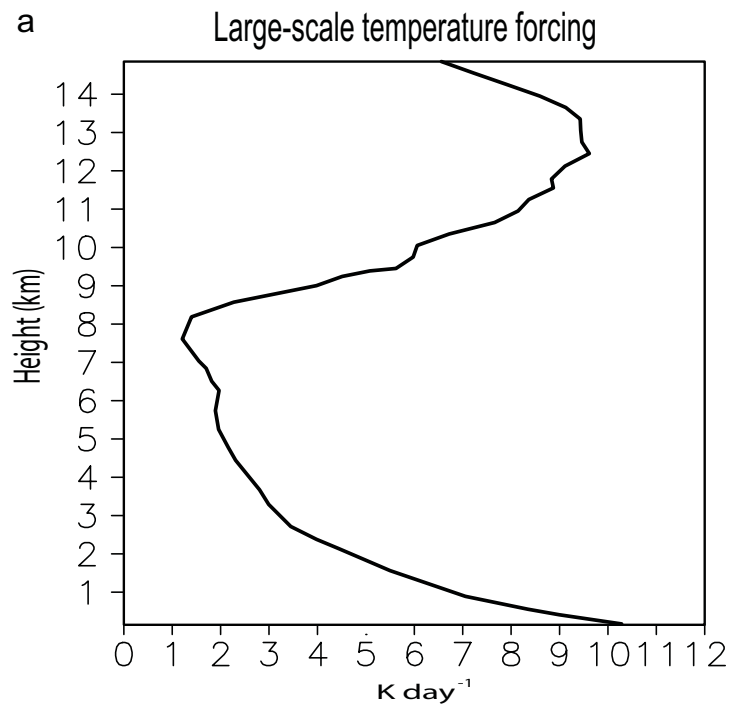

b

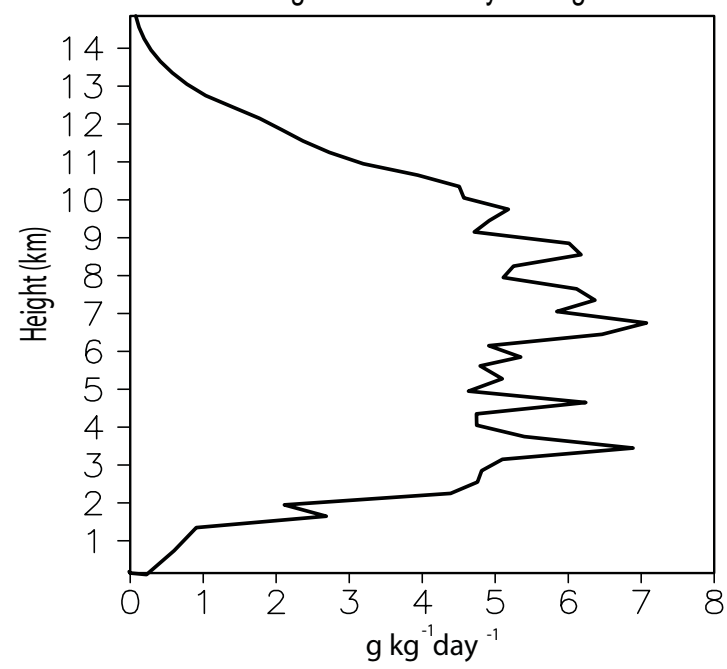

Fig. 2. Vertical distribution of the time- and area-averaged (a) potential temperature large-scale forcing and (b) humidity large-scale forcing.

aerosol is removed from the system when precipitating hydrometeors fall to the surface or returned to the atmosphere when hydrometeors evaporate or sublimate (Feingold and Kreidenweis, 2002). At each grid point which has aerosol mass returned by evaporation and sublimation, the returned mass is added to pre-existing aerosol mass. Then, aerosol number in each bin of the aerosol size distribution is determined using this total mass (returned mass + pre-existing mass), aerosol particle density, and the assumed log-normal size distribution.

The first simulation of CONTROL adopts the initial background aerosol profiles which are extracted from the Aerosol and Chemical Transport in tropIcal conVEction (ACTIVE) program (Vaughan et al., 2008) with which the TWP-ICE was coordinated. Henceforth, this simulation is referred to as

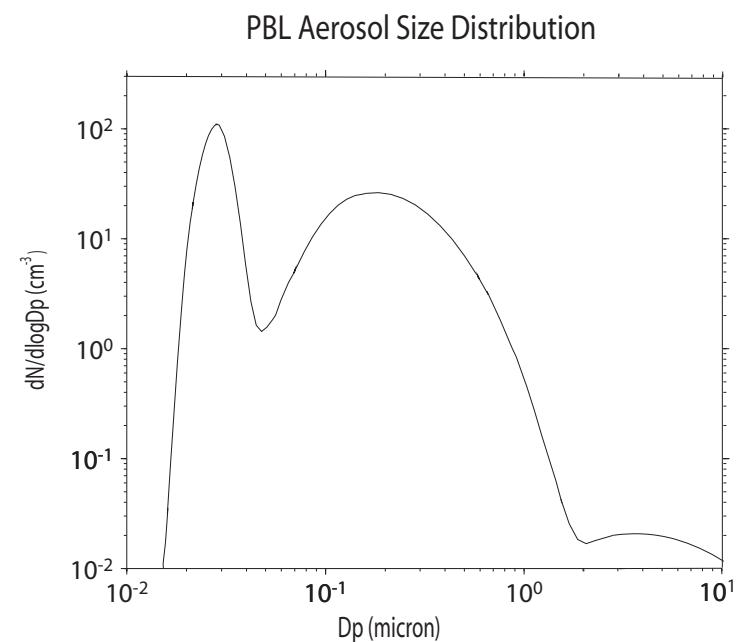

Fig. 3. Size distribution of the averaged aerosol over the PBL.

"the low-aerosol run". The size distribution and number concentration of background aerosol are calculated following the methodology described in Fridlind et al. (2009) and aerosol distributions shown in Fig. 4 in Fridlind et al. (2009) are applied. These distributions are tri-modal log-normal distributions with modal diameters of $0.03,0.18$, and 4.4 micron and with standard deviations of $1.12,1.45$, and 1.80 for nuclei, accumulation, and coarse mode, respectively. Figure 3 shows the initial background aerosol distribution averaged over the PBL. The averaged aerosol number (integrated over the distribution) over the PBL is $\sim 400 \mathrm{~cm}^{-3}$ and this represents the observed number over the PBL reasonably well during the simulation period. The background aerosol is assumed to be horizontally homogeneous at time zero but changes thereafter based on transport and cloud processes.

To examine the aerosol effect, the low-aerosol run is repeated but with only the aerosol number enhanced by a factor of 10. This simulation is referred to as "the high-aerosol run".

\section{Reduced humidity cases}

The high- and low-aerosol runs in CONTROL are repeated by varying the environmental humidity to examine the role of humidity in the effect of aerosol on precipitation.

As shown by Weisman and Klemp (1982) and Bluestein (1993), the basic type of convective clouds is determined by convective available potential energy (CAPE). CAPE is closely linked to temperature and humidity in the PBL. To minimize the variations of CAPE and thus the variations of cloud type, only humidity above the PBL varies among CONTROL and repeated simulations. This better isolates the effect of humidity on aerosol-precipitation interactions by excluding the effect of cloud type or cloud-system organization on these interactions; Seifert 


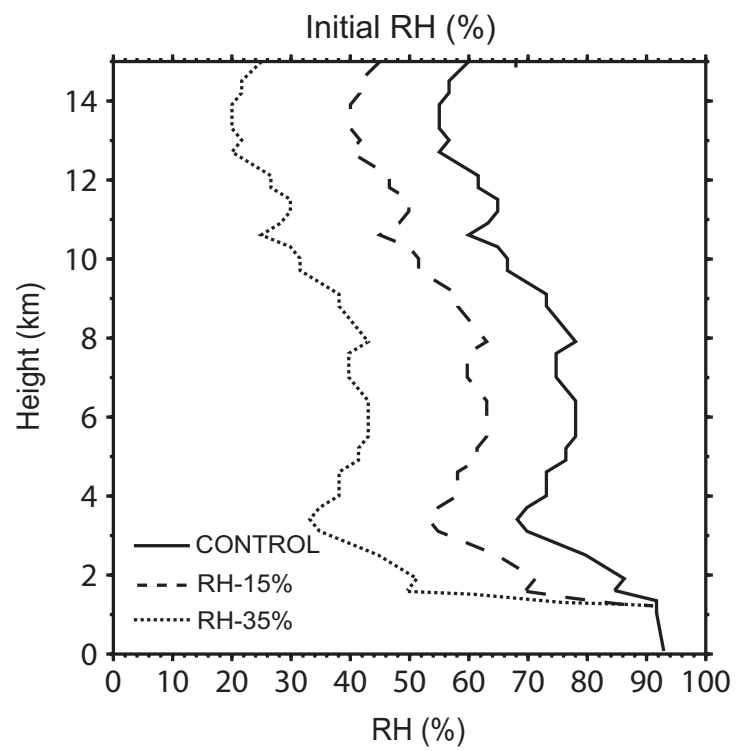

Fig. 4. Vertical profiles of initial RH.

and Beheng (2006), van den Heever et al. (2011), Lee et al. (2008a, b, 2009, 2010), and Storer et al. (2010) showed that aerosol-precipitation interactions strongly depended on the cloud-system organization.

For the first case of the repeated runs, the initial relative humidity (RH) in CONTROL, decreased by $15 \%$, is applied (Fig. 4). This case of runs is referred to as "RH-15\%". For the other case of repeated runs, the initial CONTROL humidity is reduced by $35 \%$. This case is referred to as "RH-35\%". This 35\% reduction of humidity corresponds to the variation of the average humidity above the PBL during the whole TWP-ICE campaign which lasted $\sim 20$ days. The $15 \%$ variation is chosen to represent a humidity level which is around a halfway point between the humidity level in CONTROL and that in RH-35\%. Table 1 summarizes simulations in this study. In Table 1, there are brief descriptions of supplementary simulations in addition to the high- and low-aerosol runs in each of cases. These supplementary simulations will be described in the following Sect. 5.3 in more detail.

\section{Results}

\subsection{CONTROL}

\subsubsection{Precipitation rate and cumulative precipitation}

Figure 5 depicts the time series of the area-mean precipitation rate smoothed over $3 \mathrm{~h}$ for simulations in CONTROL. The comparison of precipitation between observation and the low-aerosol run in Fig. 5 demonstrates that precipitation is simulated reasonably well. The averaged cumulative precipitation over the domain at the last time step is 86.45

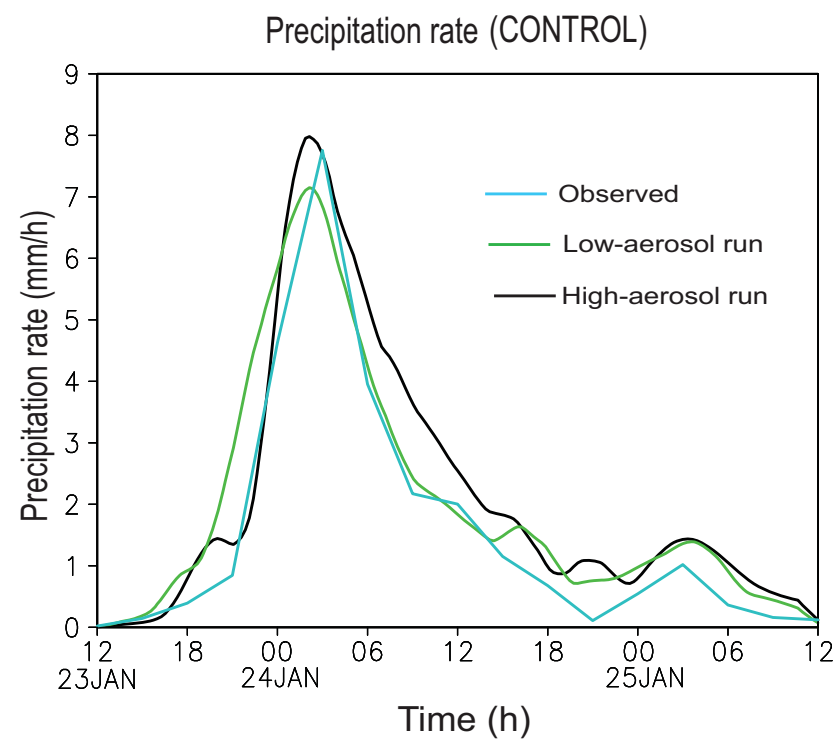

Fig. 5. Time series of the area-averaged precipitation rate.

and $83.13 \mathrm{~mm}$ for the low-aerosol run and observation, respectively. Hence, the percentage difference in precipitation between simulation and observation is less than $10 \%$, confirming the reasonable simulation of precipitation. This is partially due to the imposed large-scale forcings which constrain the simulated precipitation. The averaged cumulative precipitation over the domain at the last time step for the high-aerosol run is $94.60 \mathrm{~mm}$, which is $\sim 9 \%$ greater than that for the low-aerosol run. Increasing aerosol concentration enhances precipitation.

The precipitation event simulated here is driven by deep convective clouds as shown in Fig. 6a which depicts contours of mixing ratios of cloud liquid and cloud ice obtained at the time of the occurrence of maximum precipitation rate in the middle of the y direction in the low-aerosol run. Figure $6 \mathrm{~b}$ shows the horizontal distribution of the averaged cloud-liquid mixing ratio over the vertical domain in the low-aerosol run at the same time as Fig. 6a is obtained. Figure $6 \mathrm{~b}$ shows that cells tend to be clustered. Also, the clustered cells tend to line up diagonally in the domain, which indicates that they form an organized structure. Simulated cloud fractions averaged over the simulation period for low-, mid-, and high-clouds in the low-aerosol run are 45, 55, and $78 \%$, respectively, which is just a few percent different from observed fractions during the TWP-ICE campaign. Here, clouds between $0-5,5-10$, and $10-20 \mathrm{~km}$ in altitude are classified as low-, mid-, and high-clouds, respectively. Also, the averaged cloud-top height over the simulation period in the low-aerosol run is $8.5 \mathrm{~km}$, which shows $\sim 8 \%$ difference with the observed height during the TWP-ICE campaign. This indicates that the overall system structure is reasonably simulated. 
Table 1. Summary of simulations.

\begin{tabular}{|c|c|c|c|c|c|c|c|}
\hline \multicolumn{2}{|c|}{ Simulations } & \multirow{2}{*}{$\begin{array}{l}\text { Background } \\
\text { aerosols } \\
\text { averaged } \\
\text { over the } \\
\text { PBL } \\
\left(\mathrm{cm}^{-3}\right) \\
4000\end{array}$} & \multirow{2}{*}{$\begin{array}{l}\text { Mean } \\
\text { initial } \\
\text { background } \\
\text { RH above } \\
\text { the PBL } \\
(\%) \\
71\end{array}$} & \multirow{2}{*}{$\begin{array}{l}\text { Domain } \\
\\
125 \times 125 \times 20 \mathrm{~km}^{3}\end{array}$} & \multirow{2}{*}{$\begin{array}{l}\text { Grid spacing } \\
\\
\Delta x=\Delta y=500 \mathrm{~m} \\
\Delta z=200 \mathrm{~m}\end{array}$} & \multirow{2}{*}{$\begin{array}{l}\text { Ice physics } \\
\\
\text { Included }\end{array}$} & \multirow{2}{*}{$\begin{array}{l}\text { Downdrafts } \\
\text { No adjustment }\end{array}$} \\
\hline \multirow{7}{*}{ CONTROL } & $\begin{array}{l}\text { High-aerosol } \\
\text { run }\end{array}$ & & & & & & \\
\hline & $\begin{array}{l}\text { Low-aerosol } \\
\text { run }\end{array}$ & 400 & 71 & $125 \times 125 \times 20 \mathrm{~km}^{3}$ & $\begin{array}{l}\Delta x=\Delta y=500 \mathrm{~m} \\
\Delta z=200 \mathrm{~m}\end{array}$ & Included & No adjustment \\
\hline & $\begin{array}{l}\text { High-aerosol- } \\
\text { no-ice run }\end{array}$ & 4000 & 71 & $125 \times 125 \times 20 \mathrm{~km}^{3}$ & $\begin{array}{l}\Delta x=\Delta y=500 \mathrm{~m} \\
\Delta z=200 \mathrm{~m}\end{array}$ & Not included & No adjustment \\
\hline & $\begin{array}{l}\text { Low-aerosol- } \\
\text { no-ice run }\end{array}$ & 400 & 71 & $125 \times 125 \times 20 \mathrm{~km}^{3}$ & $\begin{array}{l}\Delta x=\Delta y=500 \mathrm{~m} \\
\Delta z=200 \mathrm{~m}\end{array}$ & Not included & No adjustment \\
\hline & $\begin{array}{l}\text { High-aerosol- } \\
\text { no-conv run }\end{array}$ & 4000 & 71 & $125 \times 125 \times 20 \mathrm{~km}^{3}$ & $\begin{array}{l}\Delta x=\Delta y=500 \mathrm{~m} \\
\Delta z=200 \mathrm{~m}\end{array}$ & Included & $\begin{array}{l}\text { Reduced to the level of } \\
\text { downdrafts in the low- } \\
\text { aerosol run at the PBL } \\
\text { top }\end{array}$ \\
\hline & $\begin{array}{l}\text { High-aerosol- } \\
100 \mathrm{~m} \text { run }\end{array}$ & 4000 & 71 & $125 \times 125 \times 20 \mathrm{~km}^{3}$ & $\begin{array}{l}\Delta x=\Delta y=100 \mathrm{~m} \\
\Delta z=100 \mathrm{~m}\end{array}$ & Included & No adjustment \\
\hline & $\begin{array}{l}\text { Low-aerosol- } \\
100 \mathrm{~m} \text { run }\end{array}$ & 400 & 71 & $125 \times 125 \times 20 \mathrm{~km}^{3}$ & $\begin{array}{l}\Delta x=\Delta y=100 \mathrm{~m} \\
\Delta z=100 \mathrm{~m}\end{array}$ & Included & No adjustment \\
\hline \multirow{7}{*}{ RH- $15 \%$} & $\begin{array}{l}\text { High-aerosol } \\
\text { run }\end{array}$ & 4000 & 56 & $125 \times 125 \times 20 \mathrm{~km}^{3}$ & $\begin{array}{l}\Delta x=\Delta y=500 \mathrm{~m} \\
\Delta z=200 \mathrm{~m}\end{array}$ & Included & No adjustment \\
\hline & $\begin{array}{l}\text { Low-aerosol } \\
\text { run }\end{array}$ & 400 & 56 & $125 \times 125 \times 20 \mathrm{~km}^{3}$ & $\begin{array}{l}\Delta x=\Delta y=500 \mathrm{~m} \\
\Delta z=200 \mathrm{~m}\end{array}$ & Included & No adjustment \\
\hline & $\begin{array}{l}\text { High-aerosol- } \\
\text { no-ice run }\end{array}$ & 4000 & 56 & $125 \times 125 \times 20 \mathrm{~km}^{3}$ & $\begin{array}{l}\Delta x=\Delta y=500 \mathrm{~m} \\
\Delta z=200 \mathrm{~m}\end{array}$ & Not included & No adjustment \\
\hline & $\begin{array}{l}\text { Low-aerosol- } \\
\text { no-ice run }\end{array}$ & 400 & 56 & $125 \times 125 \times 20 \mathrm{~km}^{3}$ & $\begin{array}{l}\Delta x=\Delta y=500 \mathrm{~m} \\
\Delta z=200 \mathrm{~m}\end{array}$ & Not included & No adjustment \\
\hline & $\begin{array}{l}\text { High-aerosol- } \\
\text { no-conv run }\end{array}$ & 4000 & 56 & $125 \times 125 \times 20 \mathrm{~km}^{3}$ & $\begin{array}{l}\Delta x=\Delta y=500 \mathrm{~m} \\
\Delta z=200 \mathrm{~m}\end{array}$ & Included & $\begin{array}{l}\text { Reduced to the level of } \\
\text { downdrafts in the low- } \\
\text { aerosol run at the PBL } \\
\text { top }\end{array}$ \\
\hline & $\begin{array}{l}\text { High-aerosol- } \\
100 \mathrm{~m} \text { run }\end{array}$ & 4000 & 56 & $125 \times 125 \times 20 \mathrm{~km}^{3}$ & $\begin{array}{l}\Delta x=\Delta y=100 \mathrm{~m} \\
\Delta z=100 \mathrm{~m}\end{array}$ & Included & No adjustment \\
\hline & $\begin{array}{l}\text { Low-aerosol- } \\
100 \mathrm{~m} \text { run }\end{array}$ & 400 & 56 & $125 \times 125 \times 20 \mathrm{~km}^{3}$ & $\begin{array}{l}\Delta x=\Delta y=100 \mathrm{~m} \\
\Delta z=100 \mathrm{~m}\end{array}$ & Included & No adjustment \\
\hline \multirow{7}{*}{ RH-35\% } & $\begin{array}{l}\text { High-aerosol } \\
\text { run }\end{array}$ & 4000 & 31 & $125 \times 125 \times 20 \mathrm{~km}^{3}$ & $\begin{array}{l}\Delta x=\Delta y=500 \mathrm{~m} \\
\Delta z=200 \mathrm{~m}\end{array}$ & Included & No adjustment \\
\hline & $\begin{array}{l}\text { Low-aerosol } \\
\text { run }\end{array}$ & 400 & 31 & $125 \times 125 \times 20 \mathrm{~km}^{3}$ & $\begin{array}{l}\Delta x=\Delta y=500 \mathrm{~m} \\
\Delta z=200 \mathrm{~m}\end{array}$ & Included & No adjustment \\
\hline & $\begin{array}{l}\text { High-aerosol- } \\
\text { no-ice run }\end{array}$ & 4000 & 31 & $125 \times 125 \times 20 \mathrm{~km}^{3}$ & $\begin{array}{l}\Delta x=\Delta y=500 \mathrm{~m} \\
\Delta z=200 \mathrm{~m}\end{array}$ & Not included & No adjustment \\
\hline & $\begin{array}{l}\text { Low-aerosol- } \\
\text { no-ice run }\end{array}$ & 400 & 31 & $125 \times 125 \times 20 \mathrm{~km}^{3}$ & $\begin{array}{l}\Delta x=\Delta y=500 \mathrm{~m} \\
\Delta z=200 \mathrm{~m}\end{array}$ & Not included & No adjustment \\
\hline & $\begin{array}{l}\text { High-aerosol- } \\
\text { no-conv run }\end{array}$ & 4000 & 31 & $125 \times 125 \times 20 \mathrm{~km}^{3}$ & $\begin{array}{l}\Delta x=\Delta y=500 \mathrm{~m} \\
\Delta z=200 \mathrm{~m}\end{array}$ & Included & $\begin{array}{l}\text { Reduced to the level of } \\
\text { downdrafts in the low- } \\
\text { aerosol run at the PBL } \\
\text { top }\end{array}$ \\
\hline & $\begin{array}{l}\text { High-aerosol- } \\
100 \mathrm{~m} \text { run }\end{array}$ & 4000 & 31 & $125 \times 125 \times 20 \mathrm{~km}^{3}$ & $\begin{array}{l}\Delta x=\Delta y=100 \mathrm{~m} \\
\Delta z=100 \mathrm{~m}\end{array}$ & Included & No adjustment \\
\hline & $\begin{array}{l}\text { Low-aerosol- } \\
100 \mathrm{~m} \text { run }\end{array}$ & 400 & 31 & $125 \times 125 \times 20 \mathrm{~km}^{3}$ & $\begin{array}{l}\Delta x=\Delta y=100 \mathrm{~m} \\
\Delta z=100 \mathrm{~m}\end{array}$ & Included & No adjustment \\
\hline
\end{tabular}



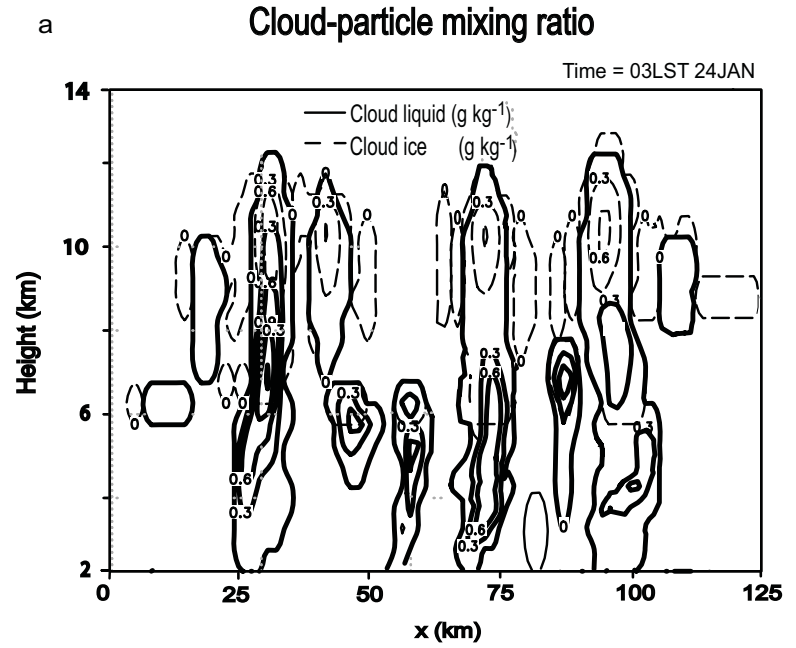

b

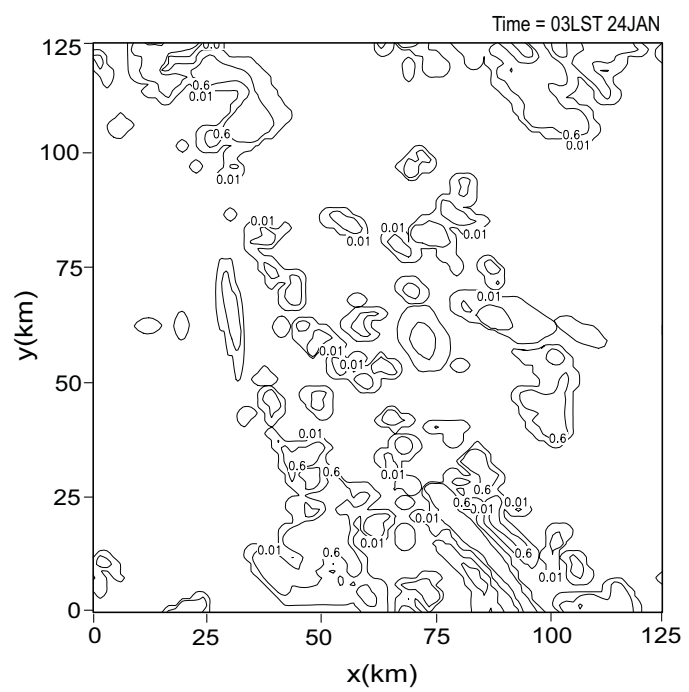

Fig. 6. (a) Contours of cloud-liquid (solid thick line) and cloud-ice (dashed line) mixing ratio $\left(\mathrm{g} \mathrm{kg}^{-1}\right)$ and (b) horizontal distribution of the averaged cloud-liquid mixing ratio over the vertical domain at the time of the occurrence of maximum precipitation rate for the low-aerosol run in CONTROL. For (a), contours are obtained in the middle of the y direction. Contour starts at $0 \mathrm{~g} \mathrm{~kg}^{-1}$ and contour interval is $0.3 \mathrm{~g} \mathrm{~kg}^{-1}$. For (b), contours are at 0.01 and $0.6 \mathrm{~g} \mathrm{~kg}^{-1}$.

At the last time step, the domain averaged background aerosol number is $\sim$ half of that at the first time step for both the high- and low-aerosol runs. In the PBL, the average number is $\sim 200$ and $\sim 2000 \mathrm{~cm}^{-3}$ for the high- and low-aerosol runs at the last time step, respectively; note that the average number is $\sim 400$ and $\sim 4000 \mathrm{~cm}^{-3}$ for the high- and lowaerosol runs at the first time step in the PBL, respectively. Also, the larger average aerosol number in the high-aerosol run than in the low-aerosol run is maintained over the whole simulation period for both places in and above the PBL; this is applicable to the other cases described in Sect. 5.2.

\subsubsection{Precipitation budget}

Microphysical processes leading to the difference in precipitation are examined by obtaining differences in the domainaveraged cumulative sources and sinks of the sum of precipitable hydrometeors between the high-aerosol run and lowaerosol run (high aerosol - low aerosol). For this, production equations for the sum of precipitable hydrometeors are integrated over the domain and duration of the simulations. The time- and domain-average tendency is zero, since the storage of the hydrometeors is zero at the end of simulation. Among the sources and sinks, autoconversion and terms associated with accretion of cloud liquid predominantly account for precipitation differences to yield the following approximate difference equation:

$$
\begin{aligned}
& \Delta\left(\left\langle\frac{\partial q_{\mathrm{r}}}{\partial t}\right\rangle+\left\langle\frac{\partial q_{\mathrm{i}}}{\partial t}\right\rangle+\left\langle\frac{\partial q_{\mathrm{a}}}{\partial t}\right\rangle+\left\langle\frac{\partial q_{\mathrm{h}}}{\partial t}\right\rangle\right)=\Delta\|\operatorname{Pr}\| \\
& \quad \approx \Delta\left\langle A u\left(q_{\mathrm{r}} ; q_{\mathrm{c}} \mid q_{\mathrm{c}}\right)\right\rangle+\Delta\left\langle A\left(q_{\mathrm{r}} ; q_{\mathrm{c}} \mid q_{\mathrm{r}}\right)\right\rangle+\Delta\left\langle A\left(q_{\mathrm{h}} ; q_{\mathrm{c}} \mid q_{\mathrm{h}}\right)\right\rangle \\
& \quad+\Delta\left\langle A\left(q_{\mathrm{i}} ; q_{\mathrm{c}} \mid q_{\mathrm{i}}\right)\right\rangle+\Delta\left\langle A\left(q_{\mathrm{h}} ; q_{\mathrm{c}} \mid q_{\mathrm{a}}\right)\right\rangle+\Delta\left\langle A\left(q_{\mathrm{h}} ; q_{\mathrm{c}} \mid q_{\mathrm{i}}\right)\right\rangle \\
& \quad+\Delta\left\langle A\left(q_{\mathrm{a}} ; q_{\mathrm{c}} \mid q_{\mathrm{a}}\right)\right\rangle
\end{aligned}
$$

where volume and area integrations are denoted by \langle\rangle and II II, respectively:

$\langle A\rangle=\frac{1}{\operatorname{LxLy}} \iiint \rho_{a} A d x d y d z d t,\|A\|=\frac{1}{\operatorname{LxLy}} \iint A d x d y d t$

$L x$ and $L y$ are the domain length, which is $125 \mathrm{~km}$, in the $\mathrm{x}$ and $\mathrm{y}$ directions, respectively. In Eq. (1), the mixing ratios of cloud liquid, cloud ice, aggregates, rain, and hail are represented by $q_{\mathrm{c}}, q_{\mathrm{i}}, q_{\mathrm{a}}, q_{\mathrm{r}}$, and $q_{\mathrm{h}}$, respectively, and $A u$ and $A$ represent autoconversion and accretion, respectively. $\mathrm{Pr}$ is precipitation. Notation for terms in budget equations obeys the following conventions: the variable before the semi-colon in each term indicates the quantity whose mixing ratio is changed by the source or sink. Following the semicolon, quantities that merge or separate in the source or sink are indicated by a "|" between them. A single variable following a semi-colon indicates a quantity whose mixing ratio is changed by a phase transition; this last convention is used in the following Eq. (1).

The terms on the right hand side of Eq. (1) are differences (high aerosol - low aerosol) in autoconversion, accretion of cloud liquid by rain to form rain, accretion of cloud liquid by hail to form hail, accretion of cloud liquid by cloud ice to form cloud ice, accretion of cloud liquid by aggregates to form hail, accretion of cloud liquid by cloud ice to form hail, and accretion of cloud liquid by aggregates to form aggregates, respectively, between the high- and low-aerosol runs. The sources and sinks excluded from Eq. (1) contribute one order of magnitude less to the differences in precipitation than sources retained in Eq. (1). Budget numbers for Eq. (1) are shown in Table 2.

The increased aerosol concentration leads to the increased precipitation. This is because the increase in accretion is larger than the decrease in autoconversion (Table 2). The 
Table 2. Domain-averaged differences in the accumulated sources and sinks of precipitation, retained in the approximated Eqs. (1) and (3), and the domain-averaged differences in the accumulated evaporation of rain between the high- and low-aerosol runs.

\begin{tabular}{|c|c|c|c|}
\hline \multirow[b]{2}{*}{ Terms in Eq. (1) } & \multicolumn{3}{|c|}{ Differences (mm) (High aerosol - Low-aerosol) } \\
\hline & CONTROL & RH- $15 \%$ & RH-35\% \\
\hline $\begin{array}{l}\left\langle A u\left(q_{\mathrm{r}} ; q_{\mathrm{c}} \mid q_{\mathrm{c}}\right)\right\rangle \\
\text { Autoconversion }\end{array}$ & -8.69 & -7.98 & -7.71 \\
\hline $\begin{array}{l}\left\langle A\left(q_{\mathrm{r}} ; q_{\mathrm{c}} \mid q_{\mathrm{r}}\right)\right\rangle \\
\text { Accretion of cloud liquid by rain } \\
\text { to form rain }\end{array}$ & 12.68 & 10.66 & 4.40 \\
\hline $\begin{array}{l}\left\langle A\left(q_{\mathrm{h}} ; q_{\mathrm{c}} \mid q_{\mathrm{h}}\right)\right\rangle \\
\text { Accretion of cloud liquid } \\
\text { by hail to form hail }\end{array}$ & 2.54 & 1.61 & 0.37 \\
\hline $\begin{array}{l}\left\langle A\left(q_{\mathrm{i}} ; q_{\mathrm{c}} \mid q_{\mathrm{i}}\right)\right\rangle \\
\text { Accretion of cloud liquid } \\
\text { by cloud ice to form cloud ice }\end{array}$ & 0.05 & 0.02 & 0.01 \\
\hline $\begin{array}{l}\left\langle A\left(q_{\mathrm{h}} ; q_{\mathrm{c}} \mid q_{\mathrm{a}}\right)\right\rangle \\
\text { Accretion of cloud liquid } \\
\text { by aggregates to form hail }\end{array}$ & 0.75 & 0.25 & 0.15 \\
\hline $\begin{array}{l}\left\langle A\left(q_{\mathrm{h}} ; q_{\mathrm{c}} \mid q_{\mathrm{i}}\right)\right\rangle \\
\text { Accretion of cloud liquid } \\
\text { by cloud ice to form hail }\end{array}$ & 0.43 & 0.21 & 0.11 \\
\hline $\begin{array}{l}\left\langle A\left(q_{\mathrm{a}} ; q_{\mathrm{c}} \mid q_{\mathrm{a}}\right)\right\rangle \\
\text { Accretion of cloud liquid } \\
\text { by aggregates to form aggregates }\end{array}$ & 0.05 & 0.03 & 0.02 \\
\hline Terms in Eq. (3) & CONTROL & RH- $15 \%$ & RH-35\% \\
\hline $\begin{array}{l}\left\langle C\left(q_{\mathrm{c}} ; q_{\mathrm{v}}\right)\right\rangle \\
\text { Condensation }\end{array}$ & 62.24 & 83.10 & 98.05 \\
\hline $\begin{array}{l}\left\langle E\left(q_{\mathrm{v}} ; q_{\mathrm{c}}\right)\right\rangle \\
\text { Evaporation of cloud liquid }\end{array}$ & 54.84 & 78.21 & 100.50 \\
\hline Evaporation of rain & CONTROL & RH- $15 \%$ & RH-35\% \\
\hline $\begin{array}{l}\left\langle E\left(q_{\mathrm{v}} ; q_{\mathrm{c}}\right)\right\rangle \\
\text { Evaporation of rain }\end{array}$ & -0.25 & -0.32 & -0.35 \\
\hline $\begin{array}{l}\|\operatorname{Pr}\| \\
\text { Precipitation }\end{array}$ & 8.15 & 5.10 & -2.79 \\
\hline
\end{tabular}

presence of increased cloud liquid is required for the larger increase in accretion. To examine the source of the increased cloud liquid, budget terms controlling the evolution of cumulative cloud-liquid mass (i.e., $\left\langle\frac{\partial q_{\mathrm{c}}}{\partial t}\right\rangle$ ) are added to those in the production equation for the sum of precipitable hydrometeors. Terms associated with cloud liquid in the production equation for the sum of precipitable hydrometeors are canceled out by this addition. Then, it is found that differences in condensation and evaporation of cloud liquid are one to three orders of magnitude larger than the other terms as in Khain et al. (2008) and Lee et al. (2008a, b). Therefore, the difference in precipitation is approximated as follows:

$\Delta\|\operatorname{Pr}\| \approx \Delta\left\langle C\left(q_{\mathrm{c}} ; q_{\mathrm{v}}\right)\right\rangle-\Delta\left\langle E\left(q_{\mathrm{v}} ; q_{\mathrm{c}}\right)\right\rangle$ 
Here, $q_{\mathrm{v}}, C$ and $E$ represent water-vapor mixing ratio, condensation and evaporation, respectively. The terms on the right hand side of Eq. (3) are differences (high aerosol - low aerosol) in condensation and evaporation of cloud liquid, respectively. Budget numbers for Eq. (3) are also shown in Table 2. Terms in the approximate Eqs. (1) and (3) together indicate that cloud liquid produced by condensation is depleted by autoconversion and accretion by precipitation as well as evaporation. Ultimately, cloud liquid disappears via evaporation. However, before its disappearance, some portion of cloud liquid is converted into precipitation via accretion and autoconversion. Autoconversion is lower at high aerosol than at low aerosol (Table 2). Note that accretion is proportional to cloud-liquid mass which is, in turn, commensurate with condensation. The combination of Eqs. (1) and (3) indicates that whether precipitation increases or decreases with the increasing aerosol concentration is determined by whether an increase in the production of cloud liquid by condensation (leading to an increase in accretion) is larger than an increase in the loss of cloud liquid by evaporation (leading to a decrease in accretion) to offset the precipitation loss from autoconversion. Here, the increased condensation of cloud liquid is greater than the increased evaporation of cloud liquid, resulting in the greater high-aerosol precipitation (Table 2).

Cumulative precipitation normalized with respect to cumulative condensation at the end of time integration is 0.33 and 0.42 in the high-aerosol run and the low-aerosol run, respectively. In spite of the lower efficiency of rain production at high aerosol, the high-aerosol run produces the larger cumulative precipitation. The increase in precipitation in this system is made possible by the increase in condensation which dominates the reduced efficiency with which cloud liquid is converted to precipitation. Condensation is closely linked to the dynamic intensity of a system. Thus, the increased condensation is likely to involve a change in the dynamics of the system between the high-aerosol and lowaerosol runs.

\subsubsection{Dynamic aspects}

Around 00:00 LST on 24 January, the precipitation rate of the high-aerosol run begins to exceed that of the low-aerosol run (Fig. 5). This leads to the larger domain-averaged cumulative rainfall of the high-aerosol run than that of the low-aerosol run at the end of the event (Table 2).

The increase in precipitation is due to an increase in the intensity of low-level convergence in the high-aerosol run as reported by Lee et al. (2008a, b). Figure 7 shows the time series of the average of $|\nabla \bullet V|$ over the horizontal domain and lowest $1 \mathrm{~km}$, where $\boldsymbol{V}$ is horizontal wind vector. Here, only $\nabla \bullet \boldsymbol{V}<0$ is included in the absolute value and average. Lowlevel convergence in the high-aerosol run begins to exceed its value in the low-aerosol run around 22:00 LST on 23 January. More convergence around the surface uplifts more air subsequently to satisfy a mass conservation. This leads to the

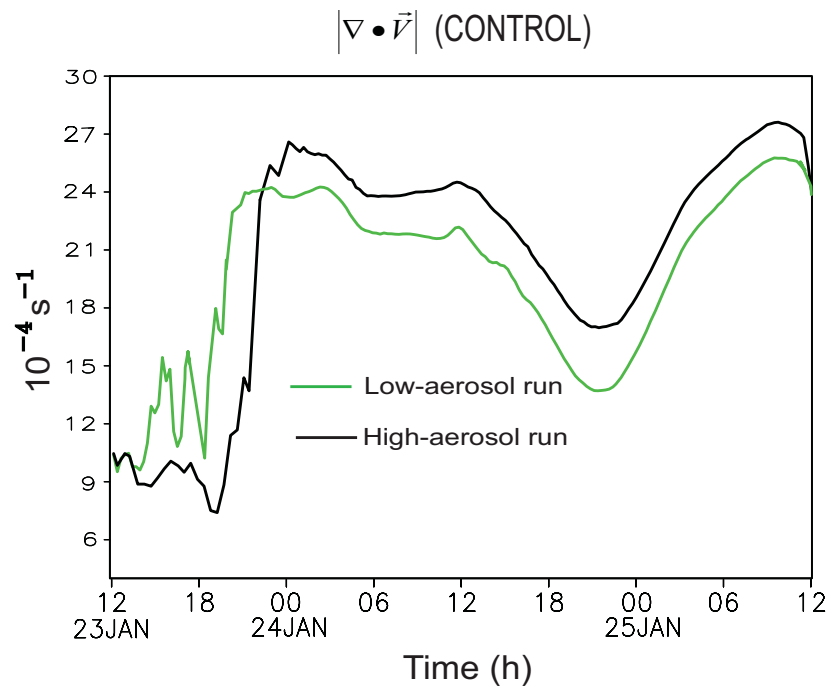

Fig. 7. Time series of averaged $|\nabla \bullet V|$ over horizontal domain at the lowest $1 \mathrm{~km}$ for the high- and low-aerosol runs in CONTROL.

development of more subsequent convective clouds as shown in Khain et al. (2005, 2008), Seifert and Beheng (2006), Tao et al. (2007) and Lee et al. (2010). As seen in Table 6, the cumulative number of convective cores is $\sim 26 \%$ larger in the high-aerosol run than in the low-aerosol run. A convective core (which is a grid column classified as the core) satisfies at least one of the following three conditions (Xu et al., 2002): (1) maximum cloud draft strength $\left(w_{\max }\right)$ is larger than the average over grid columns within $4 \mathrm{~km}$ with $w>1 \mathrm{~m} \mathrm{~s}^{-1}$, (2) $w_{\max }>3 \mathrm{~m} \mathrm{~s}^{-1}$, or (3) precipitation rate exceeds $25 \mathrm{~mm} \mathrm{~h}^{-1}$. More convective clouds produce more cumulative condensation for the enhanced cumulative precipitation through the increased averaged updrafts at high aerosol as also shown in Lee et al. (2008a, b), though the horizontal length of convective clouds, averaged over cloud depth, is smaller at high aerosol. The averaged length is 4.5 and $5.1 \mathrm{~km}$ for the highand low-aerosol runs, respectively. This smaller cloud length at high aerosol than at low aerosol is consistent with Jiang et al. (2006), Xue and Feingold (2006) and Jiang and Feingold (2006).

The evaporation of cloud liquid or rain plays an important role in controlling the intensity of convergence. Table 2 shows the domain-averaged cumulative cloud-liquid and rain evaporation. Cloud-liquid evaporation is larger at high aerosol, whereas rain evaporation is smaller at high aerosol. Consistent with Berg et al. (2008) and Storer et al. (2010), the smaller rain evaporation is due to larger raindrop sizes at high aerosol. Hence, it is the more cloudliquid evaporation which induces the more evaporative cooling, stronger downdrafts and thus the more intense low-level convergence and subsequent convective cells at high aerosol. The more cloud-liquid evaporation is initiated by less autoconversion which enhances cloud liquid as a source of 
evaporative cooling and smaller droplets which tend to provide enhanced particle surface areas for evaporation and associated cooling at high aerosol than at low aerosol. This is consistent with the findings of Lee et al. (2008a, b, 2009, 2010).

Following Jiang et al. (2006), Fig. 8a shows the vertical distribution of the $+/-$ buoyancy averaged over the cloudy regions in CONTROL. The profiles in Fig. 8 are normalized in a way that cloud base corresponds to 0 and cloud top to 1. Figure $8 \mathrm{a}$ indicates that the magnitude of both positive and negative buoyancy is larger in the high-aerosol run than in the low-aerosol run in CONTROL. The enhanced evaporative cooling (initiated by less autoconversion and smaller droplet size at high aerosol than at low aerosol) acts to enhance not only the intensity of downdrafts but also the horizontal buoyancy gradient (Fig. 8). The subsequent increase in condensation further enhances the horizontal buoyancy gradient at high aerosol. For clouds of similar size, this indicates that the horizontal buoyancy gradient is larger in the high-aerosol run than in the low-aerosol run in CONTROL. That the averaged horizontal length of clouds (for each of the $\mathrm{x}$ - and y-direction) at high aerosol is smaller than those at low aerosol confirms the larger horizontal buoyancy gradient at high aerosol than at low aerosol.

The horizontal buoyancy gradient affects vorticity as seen in the following vorticity equation:

$$
\begin{aligned}
& \frac{\partial \omega_{x}}{\partial t}=-\omega_{x}\left(\frac{\partial u}{\partial x}+\frac{\partial w}{\partial z}\right)-\frac{\partial B}{\partial x} \\
& \frac{\partial \omega_{y}}{\partial t}=-\omega_{y}\left(\frac{\partial v}{\partial y}+\frac{\partial w}{\partial z}\right)+\frac{\partial B}{\partial y}
\end{aligned}
$$

Here, $\omega_{x}$ and $\omega_{y}$ are vorticity in the $\mathrm{x}$ and $\mathrm{y}$ direction, respectively. $u$ and $v$ are the horizontal wind in the $\mathrm{x}$ and $\mathrm{y}$ direction, respectively, and $w$ is the vertical wind. $B$ is buoyancy. Thus, $\frac{\partial B}{\partial x}$ (or $B_{x}$ ) and $\frac{\partial B}{\partial y}$ (or $B_{y}$ ) are the horizontal buoyancy gradient in the $\mathrm{x}$ and $\mathrm{y}$ direction, respectively. In this study, the center of the horizontal vorticity is located at cloud edge. The magnitude of the horizontal buoyancy gradient is $\left(B_{x}^{2}+B_{y}^{2}\right)^{0.5}$. There is a divergence term (the first term on the right hand side of the vorticity equation) in addition to the horizontal-buoyancy-gradient term in the vorticity equation. As shown in Table 6 and Fig. 9a, the larger $\left(B_{x}^{2}+B_{y}^{2}\right)^{0.5}$ (calculated above the cloud base) leads to stronger vorticity in the high-aerosol run than in the low-aerosol run, indicating more entrainment of unsaturated air into clouds in the highaerosol run than in the low-aerosol run in CONTROL; note that the profiles in Fig. 9 are also normalized in the same way as in Fig. 8. However, the contribution of the divergence term (calculated above the cloud base) to vorticity and the vorticity difference between the high-aerosol run and the low-aerosol run is an order of magnitude smaller than that of the horizontal-buoyancy-gradient term (Table 6). Hence, the role of divergence in vorticity and its difference above the cloud base is considered negligible. Since large-scale
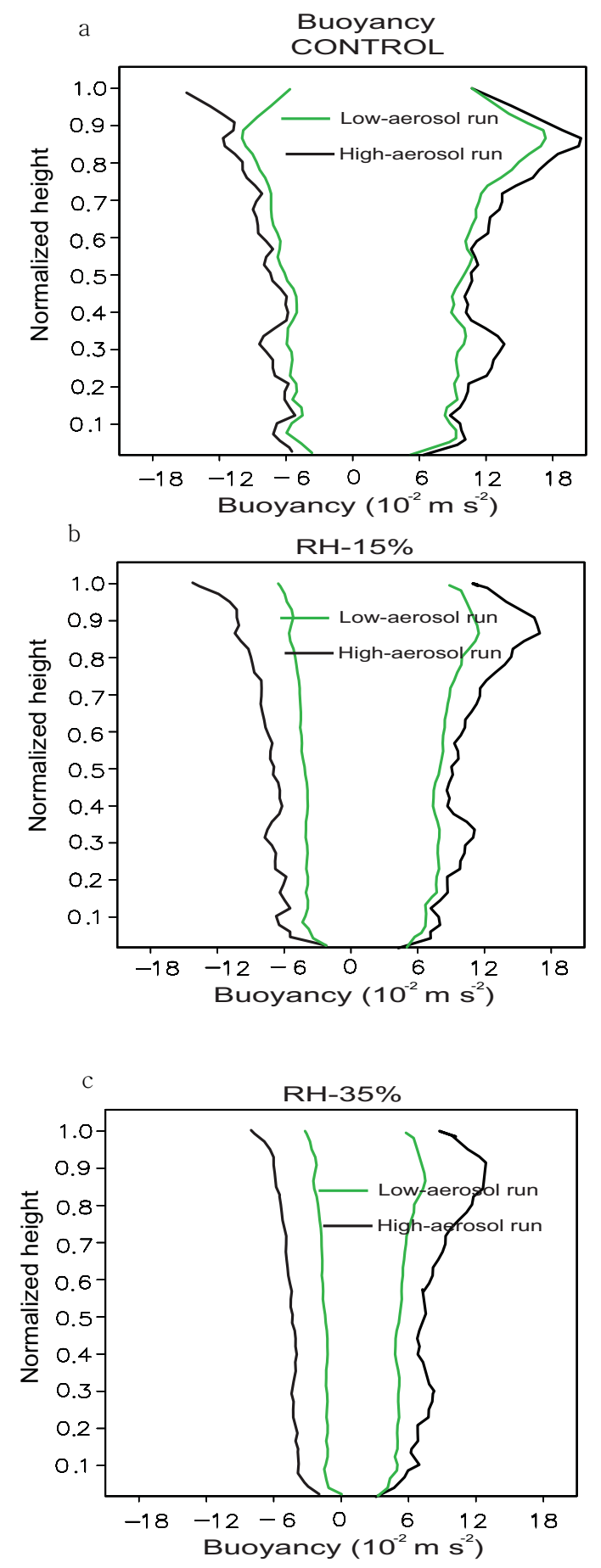

Fig. 8. Normalized profiles of buoyancy (positive and negative) for the high- and low-aerosol runs in (a) CONTROL, (b) RH-15\%, and (c) $\mathrm{RH}-35 \%$.

wind fields are identical for the high- and low-aerosol runs, they do not impact the different entrainment for the high- and low-aerosol runs. Hence, it is the turbulent-scale and cloudscale entrainment which makes differences in entrainment between the high- and low-aerosol runs. More entrainment 


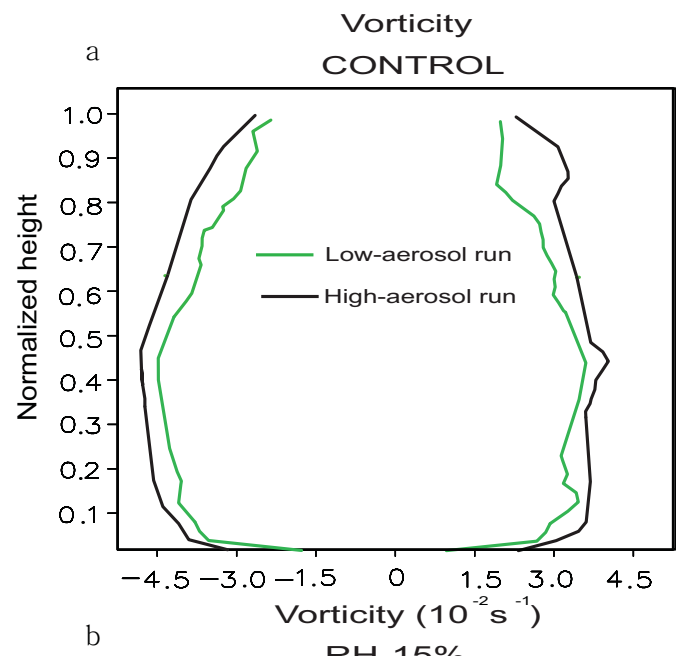

to the evaporation increase). This results in the precipitation enhancement at high aerosol in CONTROL (Table 2). One could argue that the stronger vorticity is associated not only with entrainment but also with cloud-scale and turbulentscale updrafts and, thus, the stronger vorticity can also contribute to the condensation increase at high aerosol. However, sensitivity tests show that the vorticity effect on evaporation (via entrainment) outweighs that on condensation (see the comparison between the high-aerosol-no-conv and lowaerosol runs in Sect. 5.3). Hence, it can be considered that the stronger vorticity leads to larger evaporation.

\subsection{RH-15\% and RH-35\%}

With lower environmental humidity in $\mathrm{RH}-15 \%$ as compared to CONTROL, the high-aerosol run still shows a larger cumulative precipitation than the low-aerosol run, though the difference in precipitation is smaller in $\mathrm{RH}-15 \%$ than in CONTROL (Table 2). In RH-35\% with the lowest humidity, the cumulative precipitation in the high-aerosol run is smaller than that in the low-aerosol run (Table 2).

The magnitude of the increase in condensation is larger (smaller) than that in evaporation in CONTROL and in RH$15 \%(\mathrm{RH}-35 \%)$ in the high-aerosol run. This leads to the change in the sign of the effect of aerosol on precipitation from the precipitation enhancement (as in CONTROL and $\mathrm{RH}-15 \%$ ) to the precipitation suppression (as in $\mathrm{RH}-35 \%$ ). The comparison between CONTROL and RH-15\% indicates that decreasing humidity does not necessarily lead to the precipitation suppression induced by increase in aerosol concentration.

From CONTROL to RH-15\%, the vorticity difference between the high- and low-aerosol runs increases as shown in Fig. 9 and Table 6, which is associated with more efficient evaporation due to lower humidity (leading to the larger increase in evaporation and $\left(B_{x}^{2}+B_{y}^{2}\right)^{0.5}$ induced by increase in aerosol concentration) in $\mathrm{RH}-15 \%$ than in CONTROL. However, the more efficient evaporation also leads to more efficient development of downdrafts at high aerosol. This leads to a larger difference in low-level convergence between the high- and low-aerosol runs in $\mathrm{RH}-15 \%$ than in $\mathrm{CON}$ TROL (Table 6). The effect of this larger increase in lowlevel convergence on condensation outweighs the effect of increase in vorticity and thus entrainment on evaporation, enabling the precipitation enhancement at high aerosol in $\mathrm{RH}-$ $15 \%$. However, the relative increase in condensation to that in evaporation due to the increase in aerosol concentration decreases and this leads to the decreasing precipitation difference between the high- and low-aerosol runs as humidity reduces by $15 \%$ (Table 2 ). This demonstrates that the effect of aerosol on entrainment becomes more important as humidity becomes lower.

With the lowest humidity in $\mathrm{RH}-35 \%$, the vorticity increase (and, thus, the entrainment increase) at high aerosol is the largest among the cases (Fig. 9 and Table 6). Also, as 
shown in Table 6, the increase in the intensity of low-level convergence at high aerosol is also the largest among the cases. However, in RH-35\%, the effect of the increasing entrainment on evaporation and thus on precipitation outweighs that of low-level convergence on condensation and precipitation (Table 2). This leads to the precipitation suppression induced by increase in aerosol concentration in RH-35\% (Table 2). Hence, we can see that, as humidity lowers, the effect of the entrainment increase on the precipitation response becomes stronger and, finally, dominates that of the increase in low-level convergence. This changes the sign of the precipitation response to aerosol from the precipitation enhancement (as in CONTROL and RH-15\%) to the precipitation suppression (as in $\mathrm{RH}-35 \%$ ).

\subsection{Sensitivity tests}

It is known that aerosol-precipitation interactions in deep convective clouds depend on cloud type (Seifert and Beheng, 2006; Lee et al., 2008a, b, 2009, 2010; Lee and Feingold, 2010; van den Heever et al., 2011) and ice physics (Khain et al., 2005; van den Heever et al., 2006; Lynn et al., 2007; Rosenfeld et al., 2008; Lerach et al., 2008; Khain and Lynn, 2009; Ntelekos et al., 2009; Lee et al., 2010; van den Heever et al., 2011). The aim of this study is to examine the effect of humidity on aerosol-precipitation interactions in deep convective clouds. Hence, this study does not focus on the effect of cloud type and ice physics on those interactions and the effect of humidity needs to be isolated from the effect of cloud type and ice physics. Here, the cloud-top height is selected to represent a cloud type, since the top height mainly controls the effect of aerosol on low-level convergence in convective clouds with their base around or in the PBL (Lee et al., 2008a, b, 2009, 2010).

As shown in Table 6 and as intended by applying the identical temperature and humidity in the PBL, cloud-top height obtained at the time of the maximum area-averaged precipitation rate (corresponding to the mature stage of convective clouds) does not vary significantly among the cases. This is closely linked to small variations in CAPE among simulations (Table 6); the maximum and minimum CAPE among simulations show just $\sim 10 \%$ difference. A large portion of clouds reach the tropopause at the mature stage and, thus, the averaged cloud-top height does not vary significantly even among simulations in each of the cases. Hence, the effect of cloud type on results here is considered excluded reasonably well.

\subsubsection{Ice physics}

To examine the effect of ice physics on results here, all of simulations are repeated but with no ice physics. These repeated high- and low-aerosol runs in each of the cases are named the high-aerosol-no-ice and low-aerosol-no-ice runs, respectively (Table 1 ). In the absence of ice physics, gen- erally, $\left(B_{x}^{2}+B_{y}^{2}\right)^{0.5}$, vorticity, and the intensity of low-level convergence decrease as compared to their values in the presence of ice physics (Table 6). However, we can see that $\left(B_{x}^{2}+B_{y}^{2}\right)^{0.5}$, vorcitity and the intensity of low-level convergence are still larger at high aerosol than at low aerosol with no ice physics (Table 6). Also, it is seen that the sign of the effect of aerosol on precipitation does not change in the absence of ice physics and the precipitation difference decreases as humidity lowers from CONTROL to RH-15\% (Table 3). This demonstrates that the qualitative nature of the competition between aerosol effects on entrainment and those on low-level convergence and its dependence on humidity does not depend on ice physics.

\subsubsection{Downdrafts}

To examine this competition further, we repeated the highaerosol run by artificially reducing the downdraft velocity by a fixed factor once each downdraft reaches the PBL top for each of the cases. This factor is applied when the averaged low-level convergence in the high-aerosol run starts to be larger than that in the low-aerosol run in each of the cases. This repeated high-aerosol run is referred to as the high-aerosol-no-conv run (Table 1). The factor is calculated based on the difference in the averaged downdraft intensity between the high- and low-aerosol runs. As shown in Table 6, with the reduced downdrafts at the PBL top, the low-level-convergence difference between the high-aerosolno-conv run and the low-aerosol run is $\sim$ one to two orders of magnitude smaller than that between the high- and lowaerosol runs. However, $\left(B_{x}^{2}+B_{y}^{2}\right)^{0.5}$ and vorticity in the high-aerosol-no-conv run are still significantly larger than those in the low-aerosol run. Hence, the effect of entrainment on the aerosol-precipitation interactions still exists but the effect of low-level convergence on those interactions nearly disappears between the high-aerosol-no-conv run and the low-aerosol run. The increased vorticity and thus entrainment combined with the absence of the increased intensity of low-level convergence leads to the evaporation increase that is larger than the condensation increase in the high-aerosolno-conv run in CONTROL and RH-15\% (Table 4). This leads to the precipitation suppression in the high-aerosol-noconv run, contrary to the precipitation enhancement in the high-aerosol run in CONTROL and RH-15\% (Tables 2 and 4). In RH-35\%, the precipitation suppression is enhanced in the high-aerosol-no-conv run as compared to the precipitation suppression in the high-aerosol run (Tables 2 and 4). This is due to the absence of the condensation enhancement induced by the increase in low-level convergence in the highaerosol-no-conv run in RH-35\%. This comparison between the high-aerosol-no-conv run and the high-aerosol run shows that it is the effect of the increased evaporation on low-level convergence that enables the precipitation enhancement despite the increased entrainment at high aerosol in CONTROL and $\mathrm{RH}-15 \%$. 
Table 3. Domain-averaged differences in the accumulated sources and sinks of precipitation, retained in the approximated Eqs. (1) and (3), and the domain-averaged differences in the accumulated evaporation of rain between the high-aerosol-no-ice and low-aerosol-no-ice runs.

\begin{tabular}{|c|c|c|c|}
\hline \multirow[b]{2}{*}{ Terms in Eq. (1) for no-ice cases } & \multicolumn{3}{|c|}{ Differences (mm) (High-aerosol-no-ice - Low-aerosol-no-ice) } \\
\hline & CONTROL & RH- $15 \%$ & $\mathrm{RH}-35 \%$ \\
\hline $\begin{array}{l}\left\langle A u\left(q_{\mathrm{r}} ; q_{\mathrm{c}} \mid q_{\mathrm{c}}\right)\right\rangle \\
\text { Autoconversion }\end{array}$ & -8.20 & -7.37 & -7.34 \\
\hline $\begin{array}{l}\left\langle A\left(q_{\mathrm{r}} ; q_{\mathrm{c}} \mid q_{\mathrm{r}}\right)\right\rangle \\
\text { Accretion of cloud liquid by rain } \\
\text { to from rain }\end{array}$ & 14.27 & 11.42 & 4.12 \\
\hline Terms in Eq. (3) & CONTROL & $\mathrm{RH}-15 \%$ & RH-35\% \\
\hline $\begin{array}{l}\left\langle C\left(q_{\mathrm{c}} ; q_{\mathrm{v}}\right)\right\rangle \\
\text { Condensation }\end{array}$ & 56.01 & 73.09 & 87.01 \\
\hline $\begin{array}{l}\left\langle E\left(q_{\mathrm{v}} ; q_{\mathrm{c}}\right)\right\rangle \\
\text { Evaporation of cloud liquid }\end{array}$ & 50.12 & 69.07 & 90.10 \\
\hline $\begin{array}{l}\text { Evaporation of rain for no-ice } \\
\text { cases }\end{array}$ & CONTROL & $\mathrm{RH}-15 \%$ & RH-35\% \\
\hline $\begin{array}{l}\left\langle E\left(q_{\mathrm{v}} ; q_{\mathrm{c}}\right)\right\rangle \\
\text { Evaporation of rain }\end{array}$ & -0.17 & -0.20 & -0.24 \\
\hline $\begin{array}{l}\|\operatorname{Pr}\| \\
\text { Precipitation }\end{array}$ & 6.45 & 4.12 & -3.36 \\
\hline
\end{tabular}

Table 4. Domain-averaged differences in the accumulated sources and sinks of precipitation, retained in the approximated Eq. (3) between the high-aerosol-no-conv and low-aerosol runs.

\begin{tabular}{llll}
\hline & \multicolumn{2}{c}{ Differences $(\mathrm{mm})$} & (High-aerosol-no-conv - Low-aerosol) \\
\hline Terms in Eq. (3) & CONTROL & RH-15\% & RH-35\% \\
\hline$\left\langle C\left(q_{\mathrm{c}} ; q_{\mathrm{v}}\right)\right\rangle$ & 15.56 & 37.25 & 51.30 \\
$\begin{array}{l}\text { Condensation } \\
\left\langle E\left(q_{\mathrm{v}} ; q_{\mathrm{c}}\right)\right\rangle\end{array}$ & & & \\
$\begin{array}{l}\text { Evaporation of cloud liquid } \\
\| \text { Pr } \|\end{array}$ & 17.45 & 41.40 & 58.50 \\
Precipitation & -2.05 & & -8.05 \\
\hline
\end{tabular}

\subsubsection{Resolution}

The resolution used in this study is $\sim$ one order of magnitude coarser than those generally used in the large-eddy simulation (LES) models. It is known that, as resolution becomes coarser, entrainment and aerosol effects on it become stronger (Jiang et al., 2009). However, Jiang et al. (2009) also reported that stronger vorticity and entrainment induced by increase in aerosol concentration were robust to resolutions. Hence, using coarse resolution exaggerates the effect of entrainment on clouds and aerosol impacts on it, though the sign of the effect of aerosol on entrainment is unlikely to vary with resolutions. To test the sensitivity of results here to resolutions, the high- and low-aerosol runs are repeated but with higher resolutions in each of the cases. The grid spacing for these simulations is $100 \mathrm{~m}$ for both the horizontal and vertical domains. These repeated high- and lowaerosol runs are referred to as the "high-aerosol-100 m run" and "low-aerosol-100 m run", respectively (Table 1). Table 5 shows that the precipitation differences between the high-aerosol-100 $\mathrm{m}$ run and the low-aerosol-100 $\mathrm{m}$ run are 
Table 5. Domain-averaged differences in the accumulated sources and sinks of precipitation, retained in the approximated Eq. (3) between the high-aerosol-100 $\mathrm{m}$ and low-aerosol-100 $\mathrm{m}$ runs.

\begin{tabular}{|c|c|c|c|}
\hline \multirow[b]{2}{*}{ Terms in Eq. (3) } & \multicolumn{3}{|c|}{ Differences $(\mathrm{mm})$ (High-aerosol-100 m - Low-aerosol-100 m) } \\
\hline & CONTROL & RH- $15 \%$ & $\mathrm{RH}-35 \%$ \\
\hline $\begin{array}{l}\left\langle C\left(q_{\mathrm{c}} ; q_{\mathrm{v}}\right)\right\rangle \\
\text { Condensation }\end{array}$ & 61.53 & 81.81 & 95.79 \\
\hline $\begin{array}{l}\left\langle E\left(q_{\mathrm{v}} ; q_{\mathrm{c}}\right)\right\rangle \\
\text { Evaporation of cloud liquid }\end{array}$ & 49.23 & 72.53 & 96.11 \\
\hline $\begin{array}{l}\|\operatorname{Pr}\| \\
\text { Precipitation }\end{array}$ & 12.30 & 9.28 & -0.32 \\
\hline
\end{tabular}

larger than those between the high- and low-aerosol runs in CONTROL and RH-15\%. In RH-35\%, the precipitation suppression induced by increase in aerosol concentration in the high-aerosol- $100 \mathrm{~m}$ run is smaller than that in the high-aerosol run. This is because the effect of aerosol on entrainment is weakened with the increasing resolution, while the effect of aerosol on low-level convergence is less sensitive to the resolution as shown in Table 6. However, the precipitation difference between the high-aerosol-100 $\mathrm{m}$ and low-aerosol- $100 \mathrm{~m}$ runs decreases from CONTROL to $\mathrm{RH}-15 \%$. This is because the increase of entrainment effect on the precipitation response to aerosol, induced by increase in aerosol concentration, enhances as humidity lowers from CONTROL to RH- $15 \%$ as simulated between the highand low-aerosol runs. In RH-35\%, the high-aerosol- $100 \mathrm{~m}$ run shows smaller precipitation than the low-aerosol- $100 \mathrm{~m}$ run, since the effect of increasing entrainment on evaporation outweighs that of low-level convergence on condensation as simulated between the high- and low-aerosol runs. Hence, the qualitative nature of this study is considered robust to resolutions.

\section{Conclusion and summary}

This study shows that decreasing humidity does not always lead to decreasing precipitation with increasing aerosol concentration in a deep convective system comprising multiple clouds. This is because there is a competition between increase in entrainment induced by increase in aerosol concentration and that in the intensity of low-level convergence to determine the precipitation response to aerosol. Due to decreasing autoconversion with increasing aerosol concentration, more abundant droplets as a source of evaporation are present at high aerosol than at low aerosol. Also, decreasing cloud-droplet size with increasing aerosol concentration provides increasing droplet surface areas for evaporation at high aerosol. This leads to more evaporative cooling from droplet evaporation at high aerosol. Increase in evaporative cooling induced by increase in aerosol concentration functions not only to increase entrainment (above the cloud base) but also to increase downdrafts (reaching the surface below the cloud base). The increase in entrainment acts to further increase droplet evaporation reducing cloud liquid as a source of precipitation, which tends to result in the precipitation suppression at high aerosol. The increase in downdrafts acts to intensify low-level convergence (leading to development of more, stronger subsequent secondary clouds), which enhances cloud liquid as a source of precipitation and, thus, tends to result in the precipitation enhancement at high aerosol as simulated by previous studies (e.g., Khain et al., 2005; Seifert and Beheng, 2006; van den Heever et al., 2006; van den Heever and Cotton, 2007; Tao et al., 2007; Lee et al., 2008a, b, 2009, 2010; Lee and Feingold, 2010; and Storer et al., 2010). Although humidity is reduced by $15 \%$, the effect of the increase in evaporation on downdrafts and low-level convergence, induced by the increase in aerosol concentration, outweighs that in entrainment and this enables more precipitation at high aerosol as in a case with higher humidity. However, when humidity lowers by $35 \%$, the effect of the evaporation enhancement on low-level convergence is outweighed by that on entrainment, which leads to more precipitation at low aerosol. This indicates there is a critical level of humidity from which the sign of the effect of aerosols on precipitation alters.

The humidity effect suggested by Khain et al. (2008) is based on a conceptual model of an isolated single cloud where it is not possible to see the effect of aerosol on lowlevel convergence and thus on secondary clouds. The current work indicates that the effect of humidity on aerosolprecipitation interactions on a single isolated cloud can be different from that on a system comprising multiple clouds. As described in the introduction, global hydrologic circulations are affected by MCEs comprising numerous convective cells. Hence, according to this study, the direct translation of the findings from studies for an isolated cloud to multiple-cloud systems and thus climate can be misleading. This is supported by Seifert and Beheng (2006) 
Table 6. Averaged horizontal buoyancy gradient and vorticity and terms characterizing the cloud type and the low-level convergence.

\begin{tabular}{|c|c|c|c|c|c|c|c|c|}
\hline Case & Simulation & $\begin{array}{l}\text { Average } \\
\text { cloud-top } \\
\text { height at } \\
\text { the time of } \\
\text { maximum } \\
\text { area- } \\
\text { averaged } \\
\text { precip- } \\
\text { itation } \\
(\mathrm{km})\end{array}$ & $\begin{array}{l}\text { The time- } \\
\text { and } \\
\text { domain- } \\
\text { averaged } \\
\text { CAPE } \\
\left(\mathrm{J} \mathrm{kg}^{-1}\right)\end{array}$ & $\begin{array}{l}\text { The aver- } \\
\text { aged }\left(B_{x}^{2}+\right. \\
\left.B_{y}^{2}\right)^{0.5} \text { over } \\
\text { the cloudy } \\
\text { regions } \\
\left(10^{-4} \mathrm{~s}^{-2}\right)\end{array}$ & $\begin{array}{l}\text { The aver- } \\
\text { aged mag- } \\
\text { nitude of } \\
\text { the } \\
\text { divergence } \\
\text { term over } \\
\text { the cloud } \\
\text { regions } \\
\left(10^{-5} \mathrm{~s}^{-2}\right)\end{array}$ & $\begin{array}{l}\text { The aver- } \\
\text { aged mag- } \\
\text { nitude of } \\
\text { horizontal } \\
\text { vorticity } \\
\text { over the } \\
\text { cloudy } \\
\text { regions } \\
\left(10^{-2} \mathrm{~s}^{-1}\right)\end{array}$ & $\begin{array}{l}\text { Cumulative } \\
\text { number of } \\
\text { convective } \\
\text { cores at the } \\
\text { last time } \\
\text { step }\end{array}$ & $\begin{array}{l}\text { Averaged } \\
\text { low-level } \\
\text { conver- } \\
\text { gence } \\
\text { over } \\
\text { the } \\
\text { lowest } \quad 1 \\
\text { km } \\
\left(10^{-4} \mathrm{~s}^{-1}\right)\end{array}$ \\
\hline \multirow{7}{*}{ CONTROL } & $\begin{array}{l}\text { High-aerosol } \\
\text { run }\end{array}$ & 13.2 & 2450 & 1.3 & 1.2 & 3.3 & 15155 & 20.3 \\
\hline & $\begin{array}{l}\text { Low-aerosol } \\
\text { run }\end{array}$ & 13.0 & 2300 & 1.1 & 1.0 & 3.0 & 11991 & 18.8 \\
\hline & $\begin{array}{l}\text { High-aerosol- } \\
\text { no-ice run }\end{array}$ & 13.0 & 2260 & 1.1 & 0.9 & 2.9 & 14643 & 19.2 \\
\hline & $\begin{array}{l}\text { Low-aerosol- } \\
\text { no-ice run }\end{array}$ & 12.9 & 2230 & 0.9 & 0.8 & 2.7 & 10034 & 17.6 \\
\hline & $\begin{array}{l}\text { High-aerosol- } \\
\text { no-conv run }\end{array}$ & 13.0 & 2310 & 1.2 & 1.1 & 3.2 & 12112 & 18.9 \\
\hline & $\begin{array}{l}\text { High-aerosol- } \\
100 \mathrm{~m} \text { run }\end{array}$ & 13.2 & 2490 & 1.2 & 1.4 & 3.2 & 15905 & 20.6 \\
\hline & $\begin{array}{l}\text { Low-aerosol- } \\
100 \mathrm{~m} \text { run }\end{array}$ & 13.1 & 2470 & 1.1 & 1.1 & 3.0 & 12809 & 19.1 \\
\hline \multirow{7}{*}{ RH- $15 \%$} & $\begin{array}{l}\text { High-aerosol } \\
\text { run }\end{array}$ & 13.1 & 2280 & 1.1 & 0.9 & 2.7 & 11984 & 19.3 \\
\hline & $\begin{array}{l}\text { Low-aerosol } \\
\text { run }\end{array}$ & 13.0 & 2210 & 0.7 & 0.5 & 1.8 & 9054 & 15.8 \\
\hline & $\begin{array}{l}\text { High-aerosol- } \\
\text { no-ice run }\end{array}$ & 13.1 & 2260 & 1.0 & 0.9 & 2.6 & 9886 & 18.7 \\
\hline & $\begin{array}{l}\text { Low-aerosol- } \\
\text { no-ice run }\end{array}$ & 12.9 & 2210 & 0.6 & 0.4 & 1.7 & 7588 & 14.8 \\
\hline & $\begin{array}{l}\text { High-aerosol- } \\
\text { no-conv run }\end{array}$ & 13.0 & 2250 & 1.0 & 0.7 & 2.5 & 9122 & 16.1 \\
\hline & $\begin{array}{l}\text { High-aerosol- } \\
100 \mathrm{~m} \text { run }\end{array}$ & 13.2 & 2300 & 1.0 & 0.8 & 2.5 & 12628 & 19.8 \\
\hline & $\begin{array}{l}\text { Low-aerosol- } \\
100 \text { m run }\end{array}$ & 13.1 & 2290 & 0.7 & 0.6 & 1.7 & 9579 & 16.4 \\
\hline \multirow{7}{*}{ RH-35\% } & $\begin{array}{l}\text { High-aerosol } \\
\text { run }\end{array}$ & 13.0 & 2230 & 0.9 & 0.5 & 1.6 & 8755 & 17.2 \\
\hline & $\begin{array}{l}\text { Low-aerosol } \\
\text { run }\end{array}$ & 12.8 & 2210 & 0.3 & 0.1 & 0.4 & 7621 & 13.5 \\
\hline & $\begin{array}{l}\text { High-aerosol- } \\
\text { no-ice run }\end{array}$ & 12.9 & 2220 & 0.7 & 0.4 & 1.4 & 7908 & 16.1 \\
\hline & $\begin{array}{l}\text { Low-aerosol- } \\
\text { no-ice run }\end{array}$ & 12.7 & 2200 & 0.2 & 0.1 & 0.3 & 6876 & 12.0 \\
\hline & $\begin{array}{l}\text { High-aerosol- } \\
\text { no-conv run }\end{array}$ & 12.9 & 2230 & 0.7 & 0.3 & 1.4 & 7701 & 13.7 \\
\hline & $\begin{array}{l}\text { High-aerosol- } \\
100 \mathrm{~m} \text { run }\end{array}$ & 13.1 & 2270 & 0.7 & 0.4 & 1.4 & 9212 & 17.1 \\
\hline & $\begin{array}{l}\text { Low-aerosol- } \\
100 \text { m run }\end{array}$ & 13.0 & 2250 & 0.2 & 0.2 & 0.4 & 8121 & 13.3 \\
\hline
\end{tabular}


who showed different responses of precipitation to aerosol between single-cloud systems and multiple-cloud systems. Also, it is worth pointing out that Lee and Feingold (2010) and van den Heever et al. (2011) showed that different types of clouds even in convective systems with multiple clouds responded differently to aerosol. This and the findings from this study indicate that it is difficult to establish a general rule of relationships between aerosol and clouds for parameterizations in climate models.

Results here indicate that the effect of aerosol on precipitation is not limited to microphysical modifications but extend to dynamic modifications. Dynamic modifications affect circulations (associated with downdrafts and low-level convergence) having much larger spatial and temporal scales than instantaneous microphysical responses to aerosol changes in convective cores. This indicates that the effects of aerosol perturbations can propagate into a much larger domain with a much larger time scale via changes in circulations. In other words, pollution in a small domain can be tele-connected to clouds away from it.

It needs pointing out that the intensified low-level convergence at high aerosol is associated with an increased instability in the cloud system. The increased instability is a result of cloud-scale interactions among aerosol, microphysics, and evaporation, which is not resolvable in climate models. Lee et al. (2009) and Lee and Penner (2010) showed that a cumulus parameterization in a climate model was not able to simulate the changes in instability induced by cloud-scale motions. This led to substantial errors in the simulations of liquid-water content and cloud radiative properties by the climate model. Hence, for the correct simulation of aerosolcloud interactions in convective clouds and the effect of these interactions on climate, more advanced parameterizations are required. These parameterizations should be able to consider changes in the cloud-system instability, caused not only by large-scale forcing but also by the cloud-scale interactions.

The high-aerosol-100 $\mathrm{m}$ and low-aerosol-100 $\mathrm{m}$ runs imply that the critical level of humidity is likely to be shifted to a lower value with increasing resolutions. This is because the precipitation suppression is smaller in the high-aerosol$100 \mathrm{~m}$ run than in the high-aerosol run in RH-35\%. In other words, if higher resolutions than those used in the highaerosol-100 $\mathrm{m}$ and low-aerosol-100 $\mathrm{m}$ runs were adopted, it would be possible that the precipitation enhancement occurs in RH-35\% due to more weakened aerosol effects on entrainment. This means that humidity should be lowered further to simulate the precipitation suppression at high aerosol with resolutions higher than $100 \mathrm{~m}$. However, it should be pointed out that this study does not intend to find an exact value of the critical humidity. This study intends to examine the competition between aerosol effects on entrainment and those on low-level convergence and its dependence on humidity, which has not been identified in studies on an isolated single cloud.
In this study, aerosol incorporated into hydrometeors only via nucleation (i.e., nucleation scavenging) is subject to the removal of aerosol from atmosphere by precipitation. Here, we did not include the aerosol removal by precipitation which captures aerosol (i.e., impaction scavenging), since it is known that impaction scavenging only accounts for $\sim 10 \%$ or less of the total aerosol removal by scavenging (Hobbs, 1993). Also, impaction scavenging is most effective when clouds develop heavy precipitation at their mature stages as shown by Ekman et al. $(2004,2006)$. The key mechanisms leading to stronger low-level convergence with increasing aerosol begin to operate before heavy or maximum precipitation develops as in CONTROL (cf., Figs. 5 and 7, which show the domain-mean convergence magnitude increases before the onset of heavy precipitation), so the neglect of impaction scavenging is not expected to change the qualitative nature of the results.

Enhancement in melting induced by increase in aerosol concentration intensifies downdrafts and low-level convergence together with enhancement in evaporation. Also, increase in freezing induced by the increase in aerosol concentration contributes to more cloud mass and precipitation by enhancing the parcel buoyancy (and therefore updrafts) and thus further intensifying low-level convergence (Khain et al., 2005; van den Heever et al., 2006, 2011; Lynn et al., 2007; Rosenfeld et al., 2008; Lerach et al., 2008; Khain and Lynn, 2009; Ntelekos et al., 2009; Lee et al., 2010). Hence, when ice physics and thus melting and freezing are included, the precipitation enhancement induced by the increase in aerosol concentration increases as compared to the precipitation enhancement when ice physics is not included in CONTROL and RH-15\%. In RH-35\%, the absence of updraft invigoration from the increase in freezing and the absence of downdraft invigoration from the increase in melting lead to the further suppression of precipitation with the increasing aerosol concentration. However, the variations in precipitation (with the varying aerosol concentration) in the absence of ice physics account for $\sim 75-80 \%$ of the variations in precipitation in the presence of ice physics. Thus, it can be considered that the evaporatively driven intensification of low-level convergence plays a much more important role in the precipitation difference induced by the changes in aerosol concentration than melting and freezing, which is consistent with Lee et al. (2010). This justifies the main focus of this paper, which is on the changes in the intensity of low-level convergence (induced by those in aerosol concentration and evaporative cooling) to explain the precipitation response to aerosol.

To maintain a similar cloud type (represented by the cloudtop height) and thus to isolate the dependence of aerosolcloud interactions on humidity by excluding the dependence on the cloud type, humidity in the PBL (to which CAPE and thus cloud-top height are strongly sensitive) does not vary among the cases in this study. However, if humidity in the PBL changed together with humidity above the 
PBL, variation in the precipitation response to aerosol with the varying humidity would be different than shown in this study. This is because the acceleration of downdrafts and its changes induced by those in aerosol concentration are likely to vary more significantly with the varying humidity in the PBL than with the fixed humidity in the PBL among the cases. Although it is not viable to see the sensitivity of results here to the humidity in the PBL due to the fact that the varying humidity in the PBL is likely to change the cloud type, the effect of the PBL humidity on the response of downdrafts (and low-level convergence) and thus precipitation to aerosol merits future study.

Acknowledgements. The author was funded by NOAA's Climate Goal. The author acknowledge the excellent support of NOAA's High Performance Computing Center at the Earth System Research Laboratory. Also, the author wish to thank Graham Feingold for valuable discussions and review of the manuscript.

Edited by: J. Quaas

\section{References}

Albrecht, B. A.: Aerosols, cloud microphysics, and fractional cloudiness, Science, 245, 1227-1230, 1989.

Berg, W., L'Ecuyer, T., and van den Heever, S.: Evidence for the impact of aerosols on the onset and microphysical properties of rainfall from a combination of satellite observations and cloudresolving model simulations, J. Geophys. Res., 113, D14S23, doi:10.1029/2007JD009649, 2008.

Bluestein, H. B.: Synoptic-Dynamic Meteorology in Midlatitudes: Volume II: Observations and Theory of Weather Systems (Synoptic-Dynamic Meteorology in Midlatitudes), Oxford University Press, 594 pp., 1993.

Chou, M.-D. and Suarez, M. J.: A shortwave radiation parameterization for atmospheric studies. 15, NASA/TM-104606, 40 pp., 1999.

Chou, M.-D., Ridgway, W., and Yan, M.-H: Parameterizations for water vapor IR radiative transfer in both the middle and lower atmospheres, J. Atmos. Sci., 52, 1159-1167, 1999.

Donner, L. J., Seman, C. J., and Hemler, R. S.: Three-dimensional cloud-system modeling of GATE convection, J. Atmos. Sci., 56, 1885-1912, 1999.

Ekman, A. M. L., Wang, C., Wilson, J., and Ström, J.: Explicit simulations of aerosol physics in a cloud-resolving model: a sensitivity study based on an observed convective cloud, Atmos. Chem. Phys., 4, 773-791, doi:10.5194/acp-4-773-2004, 2004.

Ekman, A. M. L., Wang, M. L. C., Wilson, J., Ström, J., and Krejci, R.: Explicit simulation of aerosol physics in a cloud-resolving model: aerosol transport and processing in the free troposphere, J. Atmos. Sci., 63, 682-696, 2006.

Feingold, G. and Kreidenweis, S. M.: Cloud processing of aerosol as modeled by a large eddy simulation with coupled microphysics and aqueous chemistry, J. Geophys. Res., 107, 4687, doi:10.1029/2002JD002054, 2002.

Forster, P., Ramaswamy, V., Artaxo, P., Berntsen, T., Betts, R., Fahey, D. W., Haywood, J., Lean, J., Lowe, D. C., Myhre, G., Nganga, J., Prinn, R., Raga, G., Schulz, M., and Van Dorland, R.:
Changes in atmospheric constituents and in radiative forcing, in: Climate change 2007: the physical science basis, Contribution of working group I to the Fourth Assessment Report of the Intergovernmental Panel on Climate Change, edited by: Solomon, S., Qin, D., Manning, M., Chen, Z., Marquis, M., Averyt, K. B., Tignor, M., and Miller, H. L., Cambridge Univ. Press, New York, 2007. Fridlind, A., Ackerman, A., Petch, J., Field, P., Hill, A., McFarquhar, G., Xie, S., and Zhang, M., Cambridge Univ. Press, New York, 2007.

Fridlind, A., Ackerman, A., Petch, J., Field, P., Hill, A., McFarquhar, G., Xie, S., and Zhang, M.: ARM/GCSS/SPARC TWPICE intercomparison study, available at: http://science.arm.gov/ $\mathrm{wg} / \mathrm{cpm} / \mathrm{scm} / \mathrm{scmic6} /$ index.html, 2009.

Grabowski, W. W., Wu, X., and Moncrieff, M. W.: Cloud resolving modeling of tropical cloud systems during phase III of GATE. Part I: Two-Dimensional Experiments, J. Atmos. Sci., 53, 3684 3709, 1996.

Hallet, J. and Mossop, S. C.: Production of secondary ice particles during the riming process, Nature, 249, 26-28, 1974.

Hobbs, P. V.: Aerosol-cloud-climate interactions, Academic Press, 233 pp., 1993.

Houze, R. A.: Cloud dynamics, Academic Press, 573 pp., 1993.

Jiang, H., Xue, H., Teller, A., Feingold, G., and Levin, Z.: Aerosol effects on the lifetime of shallow cumulus, Geophys. Res. Lett., 33, L14806, doi:10.1029/2006GL026024, 2006.

Jiang, H., Feingold, G., and Koren, I.: Effect of aerosol on trade cumulus cloud morphology, J. Geophys. Res., 114, D11209, doi:10.1029/2009JD011750, 2009.

Khain, A. and Lynn, B.: Simulation of a supercell storm in clean and dirty atmosphere using weather research and forecast model with spectral bin microphysics, J. Geophys. Res., 114, D19209, doi:10.1029/2009JD011827, 2009.

Khain, A., Rosenfeld, D., and Pokrovsky, A.: Aerosol impact on the dynamics and microphysics of deep convective clouds, Q. J. Roy. Meteor. Soc., 131, 2639-2663, 2005.

Khain, A., BenMoshe, N., and Pokrovsky, A.: Factors determining the impact of aerosols on surface precipitation from clouds: Attempt of classification, J. Atmos. Sci., 65, 1721-1748, 2008.

Klemp, J. B. and Wilhelmson, R.: The simulation of threedimensional convective storm dynamics, J. Atmos. Sci., 35, 1070-1096, 1978.

Kratz, D. P., Chou, M.-D., Yan, M.-H., and Ho, C.-H.: Minor trace gas radiative forcing calculations using the k-distribution method with one-parameter scaling, J. Geophy. Res., 103, 31647-31656, 1998.

Lee, S. S. and Feingold, G.: Precipitating cloud-system response to aerosol perturbations, Geophys. Res. Lett., 37, L23806,doi:10.1029/2010GL045596, 2010.

Lee, S. S., Donner, L. J., Phillips, V. T. J., and Ming, Y.: Examination of aerosol effects on precipitation in deep convective clouds during the 1997 ARM summer experiment, Q. J. Roy. Meteor. Soc., 134, 1201-1220, 2008a.

Lee, S. S., Donner, L. J., Phillips, V. T. J., and Ming, Y.: The dependence of aerosol effects on clouds and precipitation on cloudsystem organization, shear and stability, J. Geophys. Res., 113, D16202, doi:10.1029/2007JD009224, 2008b.

Lee, S. S., Donner, L. J., and Phillips, V. T. J.: Sensitivity of aerosol and cloud effects on radiation to cloud types: comparison between deep convective clouds and warm stratiform 
clouds over one-day period, Atmos. Chem. Phys., 9, 2555-2575, doi:10.5194/acp-9-2555-2009, 2009.

Lee, S. S., Donner, L. J., and Penner, J. E.: Thunderstorm and stratocumulus: how does their contrasting morphology affect their interactions with aerosols?, Atmos. Chem. Phys., 10, 68196837, doi:10.5194/acp-10-6819-2010, 2010.

Lerach, D. G., Gaudet, B. J., and Cotton, W. R.: Idealized simulations of aerosol influences on tornadogenesis, Geophys. Res. Lett., 35, L23806, doi:10.1029/2008GL035617, 2008.

Lynn, B. H., Khain, A. P., Rosenfeld, D., and Woodley, W. L.:Effects of aerosols on precipitation from orographic clouds, J. Geophys. Res., 112, D10225, doi:10.1029/2006JD007537, 2007.

May, P. T., Mather, J. H., Vaughan, G., and Jakob, C.: Characterizing oceanic convective cloud systems-The Tropical Warm Pool International Cloud Experiment, B. Am. Meteorol. Soc., 89, 153-155, doi:10.1175/BAMS-89-2-153, 2008.

Ntelekos, A. A., Smith, J. A., Donner, L., Fast, J. D., Gustafson Jr., W. I., Chapman, E. G., and Krajewski, W. F.: The effects of aerosols on intense convective precipitation in the northeastern United States, Q. J. Roy. Meteor. Soc., 135, 1367-1391, 2009.

Rosenfeld, D., Lohmann, U., Raga, G. B., O’Dowd, C. D., Kulmala, M., Fuzzi, S., Reissell, A., and Andreae, M. O.: Flood or drought: How do aerosols affect precipitation?, Science, 321, 1309-1313, 2008.

Ramaswamy, V., Boucher, O., Haigh, J., Hauglustaine, D., Haywood, J., Myhre, G., Nakajima, T., Shi, G. Y., and Solomon, S.: Radiative forcing of climate change, in: Climate Change 2001: The Scientific Basis, edited by: Houghton J. T., Ding, Y., Griggs, D. J., Noguer, M., van der Linden, P., Dai, X., Maskell, K., and Johnson, C. A., 349-416, Cambridge Univ. Press, New York, 2001.

Saleeby, S. M. and Cotton, W. R.: A large-droplet mode and prognostic number concentration of cloud droplets in the Colorado state university regional atmospheric modeling system (RAMS). Part I: Module description and supercell test simulations, J. Appl. Meteor., 43, 182-195, 2004.

Seifert, A. and Beheng, K. D.: A double-moment cloud microphysics parameterization for mixed-phase clouds. Part 2: Maritime vs. continental deep convective storms, Meteor. Atmos. Phys., 92, 67-82, 2006.

Simpson, J. and Tao, W.-K.: The Goddard Cumulus Ensemble model. Part II: Applications for studying cloud precipitating processes and for NASA TRMM, Terr. Atmos. Ocean. Sci., 4, 73116, 1993.

Soong, S.-T. and Ogura, Y.: Response of trade wind cumuli to largescale processes, J. Atmos. Sci., 37, 2035-2050, 1980.

Storer, R. L. van den Heever, S. C., and Stephens, G. L.: Modeling aerosol impacts on convection under differing storm environments, J. Atmos. Sci., 67, 3904-3915, 2010.

Tao, W.-K. and Simpson, J.: The Goddard Cumulus Ensemble model. Part I: Model description. Terr. Atmos. Ocean. Sci., 4, 19-54, 1993.
Tao, W.-K., Simpson, J., Baker, D., Braun, S., Chou, M.-D., Ferrier, B., Johnson, D., Khain, A., Lang, S., Lynn, B., Shie, C.-L., Starr1, D., Sui, C.-H., Wang, Y., and Wetzel1, P.: Microphysics, radiation and surface processes in the Goddard Cumulus Ensemble (GCE) model, Meteor. Atmos. Phys., 82, 97-137, 2003.

Tao, W.-K., Li, X., Khain, A., Matsui, T., Lang, S., and Simpson, $\mathrm{J}$.: The role of atmospheric aerosol concentration on deep convective precipitation: cloud-resolving model simulations, J. Geophys. Res., 112, D24S18, doi:10.1029/2007JD008728, 2007.

Twomey, S.: The influence of pollution on the shortwave albedo of clouds, J. Atmos. Sci., 34, 1149-1152, 1977.

van den Heever, S. C. and Cotton, W. R.: Urban aerosol impacts on downwind convective storms, J. Appl. Meteor. Climatol., 46, 828-850, 2007.

van den Heever, S. C., Carrio, G. G., Cotton, W. R., DeMott, P. J., and Prenni, A. J.: Impacts of nucleating aerosol on Florida Storms. Part I: Mesoscale Simulations, J. Atmos. Sci., 63, 17521775, doi:10.1175/JAS3713.1, 2006.

van den Heever, S. C. and Cotton, W. R.: Urban aerosol impacts on downwind convective storms, J. Appl. Meteor. Climatol., 46, 828-850, 2007.

van den Heever, S. C., Stephens, G. L., and Wood, N. B.: The impacts of enhanced cloud condensation nuclei concentrations on tropical convection characteristics under conditions of radiative convective equilibrium, J. Atmos. Sci, in press, 2011.

Vaughan, G., Schiller, C., MacKenzie, A. R., Bower, K. N., Peter, T., Schlager, H., Harris, N. R. P., and May, P. T.: Studies in a natural laboratory: High-altitude aircraft measurements around deep tropical convection, B. Am. Meteorol. Soc., 88, 647-662, 2008.

Walko, R. L., Cotton, W. R., Meyers, M. P., and Harrington, J. Y.: New RAMS cloud microphysics parameterization: Part I. The single-moment scheme, Atmos. Res., 38, 29-62, 1995.

Weisman, M. L. and Klemp, J. B.: The dependence of Numerically Simulated Convective Storms on Vertical Wind Shear and Buoyancy, Mon. Weather Rev., 110, 504-520, 1982.

Xu, K.-M., Cederwall, R. T., Donner, L. J., Grabowski, W. W., Guichard, F., Johnson, D. E., Khairoutdinov, M., Krueger, S. K., Petch, J. C., Randall, D. A., Seman, C. J., Tao, W.-K., Wang, W., Xie, S., Yio, J. J., and Zhang, M.-H.: An intercomparison of cloud-resolving models with the Atmospheric Radiation Measurement summer 1997 Intensive Observation Period data, Q. J. Roy. Meteor. Soc., 128, 593-624, 2002.

Xue, H. and Feingold, G.: Large-eddy simulations of trade wind cumuli: Investigation of aerosol indirect effects, J. Atmos. Sci., 63, 1605-1622, 2006. 